\title{
The Presentation of Self as Good and Right: How Value Propositions and Business Model Features are Linked in the Sharing Economy
}

\author{
Dominika Wruk ${ }^{1} \cdot$ Achim Oberg $^{1}$ (1) $\cdot$ Jennifer $\mathrm{Klutt}^{2} \cdot$ Indre Maurer $^{2}$
}

Received: 5 January 2018 / Accepted: 27 May 2019 / Published online: 23 July 2019

(c) The Author(s) 2019

\begin{abstract}
The sharing economy as an emerging field is characterized by unsettled debates about its shared purpose and defining characteristics of the organizations within this field. This study draws on neo-institutional theory to explore how sharing organizations position themselves vis-à-vis such debates with regard to (1) the values these organizations publicly promote to present themselves as "good" sharing organizations and (2) the business model features they make visible to appear as having the "right" organizational model. This study examines the online self-representations of 62 prototypical sharing organizations in Germany with regard to value propositions and business model features. A semantic network analysis of the features reveals two distinct categories of sharing organizations: grassroots initiatives and platform-based organizations. By showing how value propositions and business model features are linked in the sharing economy, the findings indicate the different legitimation strategies of grassroots initiatives and platform-based organizations, which we term "sustainability by model" and "sustainability by feature." These findings broaden our understanding of the strategies that organizations apply to cope with societal expectations in the emerging sharing economy.
\end{abstract}

Keywords Sharing economy · Institutional theory · Value proposition · Legitimation strategy $\cdot$ Semantic network analysis · Business model features

\section{Introduction}

The recent financial and economic crisis has stimulated a search for new sustainable business models and for ways to adapt existing economic models to bring about more benefits to society (Bolton and Hannon 2016; Boons and Lüdeke-Freund 2013; Geels et al. 2008). Some social-market economies in central and northern Europe have started transforming their economies into social-ecological market

Achim Oberg

oberg@ifm.uni-mannheim.de

Dominika Wruk

wruk@ifm.uni-mannheim.de

Jennifer Klutt

jennifer.klutt@wiwi.uni-goettingen.de

Indre Maurer

Indre.Maurer@wiwi.uni-goettingen.de

1 Institut für Mittelstandsforschung, University of Mannheim, L 9, 1-2, 68161 Mannheim, Germany

2 Georg-August-University Göttingen, Platz der Göttinger Sieben 3, 37073 Göttingen, Germany economies (Benecke 2008). The new models of sharing, swapping, trading, and lending-generally known as the "sharing economy" (Botsman and Rogers 2010)—have led economic and political actors to ask themselves whether business models of sharing-economy organizations represent the type of new sustainable models with the potential to sustainably advance economies (Heinrichs 2013; Martin 2016). These discussions involve two analytically distinct aspects of new organizations: (1) whether these organizations contribute to social, ecological, and economic goals and (2) which practices, processes, and tools they employ to achieve these goals.

The debate on the potential of sharing organizations to contribute to social, ecological, and economic goals is heated and often confrontational. Some believe that these business models support a more efficient use of natural resources and enable more people to participate in and profit from economic activities (Botsman and Rogers 2010). According to this view, the sharing economy contributes to achieving social and ecological values and supports transformation of the economy toward sustainability (Heinrichs 2013). Others point to the negative impacts sharing models 
have on society because they commoditize social interactions, worsen working conditions, and lead to greater consumption of natural resources (Morozov 2013). According to this view, the sharing economy is the start down an alarming pathway that leads to "hyper-capitalism" and a "neoliberal nightmare" (Martin 2016; Scholz 2016).

Closely related to the debate on the social, ecological, and economic potential of sharing-economy models is a discussion about how organizations can truly fulfill these values. Although participants in this debate generally agree that sharing-economy organizations will play an important role in the future development of economies, there is much less agreement about which organizational model is the right one for achieving desirable ends (Heinrichs 2013). On one extreme are academics, bloggers, and mass-media commentators whose strong rhetoric labels some sharing-economy organizations the "wrong" model. These contributors have described large, for-profit, and globally active organizations as the "dark side of the sharing economy" (Malhotra and Van Alstyne 2014; Rinne 2018), "death stars" (Gorenflo 2015), and "pseudo-sharing" organizations (Belk 2014). Researchers and thinkers who use less-heated rhetoric argue that before we distinguish the "right" models from the "wrong" ones, we need a better understanding of sharing organizations' business models (Schor 2014; Slee 2017).

At the center of these heated and unresolved debates are the sharing-economy organizations themselves, which are confronted with the hopes and expectations that they engender among their many stakeholders (Freeman 2010; Freeman and Reed 1983). These debates-(1) whether organizations in the sharing economy can promote social, ecological, and economic values and (2) how their business models should support such values - can have significant implications for sharing organizations' continued viability by either strengthening or weakening their legitimacy and stakeholder support (Meyer and Rowan 1977). At the same time, these debates may be an opportunity for sharing organizations to position themselves in such a way that they actually strengthen their legitimacy (Suchman 1995). The opportunity lies in the form of communication tactics (Castelló et al. 2016), justification (Whelan and Gond 2017), and legitimation strategies (Suchman 1995) that sharing organizations employ.

While recent research has characterized the general debates about the sharing economy (Cheng 2016; Cheng et al. 2016; Martin 2016), there is little systematic knowledge about the legitimation strategies sharing organizations apply to position themselves publicly in light of these debates. More concretely, we know that how organizations present themselves on the Internet is immensely important, because it allows them to communicate their purposes and their way of operating and thus to position themselves in debates (De Bakker and Hellsten 2013; Powell et al. 2016). However, we have little systematic knowledge about which values sharing-economy organizations promote and which elements of their organizational models they communicate-in particular, which features of their business models to create and capture value (Lepak et al. 2007; Yunus et al. 2010) they present publicly. With these questions in mind, our goal in this paper is to answer the following exploratory question: How are value propositions and business model features linked in the self-representation of sharing-economy organizations?

To answer this question, we draw on neo-institutional theory revealing the possibilities that exist for organizations to represent themselves in public debates about crucial issues (Hoffman 1999). We use semantic network analysis (Carley and Kaufer 1993; Carley and Palmquist 1992) to analyze how 62 prototypical sharing organizations in Germany present themselves on the Internet regarding two hotly debated aspects of these organizations: (1) the values these organizations publicly promote to present themselves as "good" sharing organizations and (2) the business model features they make visible to appear as having the "right" organizational model. By showing how value propositions and business model features are linked in the sharing economy, this study reveals two general legitimation strategies ("sustainability by model" and "sustainability by feature") that organizations in the sharing economy apply to cope with societal expectations.

\section{Organizational Positioning in Sharing-Economy Debates as "good" and "right"}

To characterize the current state of debates in the sharing economy, to conceptualize how these debates affect organizations, and to understand the possibilities organizations have to position themselves vis-à-vis expectations stemming from these debates, neo-institutional theory provides a set of helpful concepts.

\section{Neo-Institutional Perspective on Values and Features}

From this theoretical lens, the values and features of individual organizations are affected by those organizations that belong - based on a shared purpose - to the same organizational field (DiMaggio and Powell 1983). To fulfill the shared purpose, organizations in the field interact with each other and negotiate responsibilities and expectations among each other. Among the members of the field are organizations that provide the field's infrastructure (such as regulators and business associations) and internal field observers (including analysts, researchers, and media) involved in 
discussing current issues (Hinings et al. 2017; Hoffman 1999).

Over time, ongoing debates about organizations' goals and processes in a field become detached from individual organizational cases in a process of abstraction and theorization (Strang and Meyer 1993). The abstraction starts with organizational models, which typify single cases into models that cover elements of organizational structure, and processes to generate and capture value. These "models may be thought of as being intermediate to abstract dimensions of organizational form" (Clemens 1993, p. 758). Organizational forms become taken for granted in the last stage of institutionalization and help to distinguish organizations of a field into categories.

Each category represents a negotiated consensus on the set of features that organizations of that category have in common (Durand and Paolella 2013). A category is fully established when outside audiences of a field, such as potential and actual customers, and other field members reach a consensus about a necessary set of features and when organizations of that category repeatedly mirror this set (Hsu and Hannan 2005). The features of a necessary set are in many cases field-specific (Rao et al. 2005), but some features appear across fields (McKelvey 1982; McKelvey and Aldrich 1983).

Once categories emerge, members and observers can use the necessary features of a category as an evaluative framework to determine whether specific organizations are members of that category (Ruef and Patterson 2009). When organizations can clearly be assigned to one category because their combination of features strongly resembles the expected set of features, they are rewarded with approval and legitimacy (Hsu 2006; Zuckerman 1999). In turn, organizations that deviate from the set of features risk losing legitimacy (Hsu and Hannan 2005). If an organization is not able to fulfill all necessary expectations, promising to do so can serve as a proxy for such unfulfilled expectations (Meyer and Rowan 1977; Suchman 1995). As an organization is evaluated from outside by other field members and audiences of the field, the organization's self-representation in the field and toward audiences-for instance, on the Internet-becomes a crucial means to mirror expected features of the category to which the organization wants to belong.

Because categories contain a limited set of legitimate features, they narrow evaluators' focus of attention to this limited set on which they base their evaluations of legitimacy (Durand and Paolella 2013). They reduce complexity for both members of the field and outside audiences. For members of the field, categories limit the number of possible organizational forms they can choose from. The set of features establishes boundaries and offers potential members a blueprint for how to design an organization that legitimately belongs to that category (Meyer and Rowan 1977).
For observers and audiences, a field-specific set of categories serves as a set of cognitive schemata that makes it easier to compare and evaluate a large number of organizations (DiMaggio 1997).

In emerging fields such as the sharing economy (Cohen and Muñoz 2016; Hamari et al. 2016), the purpose of the field and the categories within it are debated by members and audiences who have an interest in the outcome of the debate (Clemens 1993). They propose-or sometimes even try to impose-various goals and values that they believe should constitute the shared purpose of the field. Furthermore, they try to legitimize or delegitimize specific organizational characteristics and features. With regard to the sharing economy, this is reflected in the recent debates about values and features, which we present below.

\section{Debates About Values}

To assess debates about the purpose of the sharing economy and about values sharing organizations are expected to pursue, we reviewed existing literature on the sharing economy (Boell and Cecez-Kecmanovic 2014; Hart 2018). We started by reviewing early work and basic literature on the sharing economy-such as the work of Weitzman (1984) or Botsman and Rogers (2010)—and developed a coding scheme with four categories: "Purpose of the sharing economy" entails aggregated claims about goals of the sharing economy (DiMaggio and Powell 1983). "Object of reference" captures what should be adapted to bring about the suggested change. "Key mechanisms" summarize how changes of the objects of reference can be realized. "Types of values" refer to the promoted goals and values encompassing social values, such as the reduction of inequality (Schor 2017); ecological values, such as the lowering of $\mathrm{CO} 2$ emissions (Martin and Shaheen 2011); economic values, such as the provision of new income sources (Sundararajan 2014); and combinations of these three (Schor 2014). We proceeded with searching, reading, and coding contributions in literature on the sharing economy until we reached a point of saturation where we could not identify new codes within the four categories. Then, we aggregated the analyzed contributions based on similarities regarding the four categories and recurring literature references. As a result, we identified three perspectives from which the purpose of the sharing economy is debated. In what follows, we provide ideal-type descriptions of contributions that can be assigned to one of the three perspectives and summarize them in Table 1.

The first perspective is based on the idea that the purpose of the sharing economy is to bring about an alternative to existing economic models. We therefore call the perspective the "alternative economy" perspective. Proponents of this perspective argue that the sharing economy allows for a 
Table 1 Summary of perspectives

\begin{tabular}{|c|c|c|c|c|}
\hline Perspective & $\begin{array}{l}\text { Purpose of the sharing } \\
\text { economy }\end{array}$ & Subject to change & $\begin{array}{l}\text { Key mechanisms for creat- } \\
\text { ing value }\end{array}$ & Types of values emphasized \\
\hline Alternative economy & $\begin{array}{l}\text { Create an alternative } \\
\text { economic system that } \\
\text { emphasizes social and } \\
\text { ecological values }\end{array}$ & $\begin{array}{l}\text { Production and economic } \\
\text { system, social order of } \\
\text { "collaborative commons" }\end{array}$ & $\begin{array}{l}\text { Political and economic } \\
\text { reforms, collabora- } \\
\text { tive social practices for } \\
\text { governing production and } \\
\text { resource management }\end{array}$ & Social (and ecological) \\
\hline Sustainability transition & $\begin{array}{l}\text { Change consumption } \\
\text { behavior to achieve } \\
\text { transition towards more } \\
\text { sustainability }\end{array}$ & $\begin{array}{l}\text { Socio-technical regimes, } \\
\text { social practices }\end{array}$ & $\begin{array}{l}\text { Cultural shift, diffusion of } \\
\text { sustainable consumption } \\
\text { practices }\end{array}$ & Ecological (and social) \\
\hline Business model innovation & $\begin{array}{l}\text { Open up economic } \\
\text { opportunities and release } \\
\text { economic value }\end{array}$ & $\begin{array}{l}\text { Business principles, busi- } \\
\text { ness models of organiza- } \\
\text { tions }\end{array}$ & $\begin{array}{l}\text { Unleashing previously } \\
\text { untapped economic } \\
\text { value, matching supply } \\
\text { and demand, reduction of } \\
\text { transaction costs }\end{array}$ & Economic \\
\hline
\end{tabular}

more inclusive, collaborative, and fairer production and economic system and a new social order (e.g., Bauwens 2005; Benkler 2017; Rifkin 2014; Sundararajan 2013). Weitzman (1984) laid the foundation for this perspective when he introduced the term "share economy" and argued that the mechanism of profit sharing between owners and employees incentivizes the behavior of both in a way that helps to prevent unemployment and inflation and bring about overall positive welfare effects. To realize Weitzman's ideas would require political and economic reforms of the existing system. More recently (and relatedly), some authors have even stated that the sharing economy may bring about the end of capitalism (e.g., Benkler 2017; Rifkin 2014; Sundararajan 2013). These authors suggest that a collaborative system of production, governance, and resource management, as well as collaborative social practices, will gain prominence, changing the existing economic system by creating a more democratic, just, and inclusive social order that they call "collaborative commons." The underlying concept of human well-being focuses on social values such as collaboration, solidarity, social cohesion, equality, and participation. This perspective primarily argues that the purpose of the sharing economy should be to create an alternative economic system that emphasizes social values (and ecological values) over economic ones (e.g., Benkler 2017; Rifkin 2014).

The second perspective argues that the sharing economy disrupts existing socio-technical regimes and social practices and provides a more sustainable alternative for production and consumption (e.g., Botsman and Rogers 2010). We therefore call this perspective the "sustainability transition" perspective (e.g., Geels 2002, 2011). The central mechanism to achieve the suggested changes is a cultural shift, from one of owning products to one of sharing access to them. Shared access leads to reduced consumption, production, and thus environmental pollution.
This perspective also assumes that individuals participating in the sharing economy are driven by ecological motives and consume more sustainably (Hamari et al. 2016). Proponents of this perspective (e.g., Cohen and Muñoz 2016; Voytenko Palgan et al. 2017) argue that as sharing practices diffuse from niches to mass markets, sustainable behaviors might be taken for granted and at some point even become the dominant everyday practices in a society. This view posits that the sharing economy can help to overcome potential trade-offs between economic, ecological, and social values (e.g., Agyeman 2013) and that the purpose of the field is to facilitate a transition to greater sustainability by encouraging members of society to act on ecological (and social) values.

The third perspective focuses on the merits of digitalization and innovative business models (e.g., Amit and Zott 2012; Brynjolfsson et al. 2003; Brynjolfsson and Saunders 2009; Weill and Woerner 2015). We therefore call it the "business model innovation" perspective. In this view, societal and economic change can be realized through innovating business principles and the way organizations create and capture value. Proponents claim that sharing organizations are beneficial because they use innovative business models to create economic value by unleashing previously untapped value from privately owned resources (e.g., Belk 2010, 2014; Hamari et al. 2016). The more efficient matching of supply and demand reduces transaction costs, which in turn leads to new sources of income and welfare for consumers. Furthermore, innovative business models typically yield both competitive advantages and public attention and recognition. According to this perspective, the purpose of the sharing field is primarily to open up economic opportunities and release economic value by leveraging innovative business models. In sum, this perspective emphasizes the economic values of the sharing economy. 
The three perspectives suggest different-although overlapping-purposes of the sharing economy and include alternative combinations of legitimate social, ecological, and economic values ranging from mostly social values to mostly ecological or economic ones. Existing sharing-economy literature sometimes draws on more than one of these perspectives. For instance, Schor (2014) suggests that the sharing economy could be an important component of a small-scale, ecologically sustainable economy, thus aligning the alternative economy and the sustainability transition perspective. Kenney and Zysman's (2016) depiction of a utopian version of the sharing economy suggests an alignment of the alternative economy and the business model innovation perspectives. Despite these efforts toward aligning diverging views (Whelan and Gond 2017) on the purpose of the sharing economy, no single combination seems to dominate existing debates. In turn, through combining arguments from more than one perspective, even more potentially legitimate value combinations are suggested (e.g., social-ecological, social-economic). We conclude that the debates about the sharing economy have not come to a halt or to a consensus on a shared purpose- a conclusion that is supported in current literature (Mair and Reischauer 2017).

\section{Debates About Features}

Since early debates about the sharing economy, more and more categorization systems for sharing organizations have been proposed (Voytenko Palgan et al. 2017). Early approaches to categorization grouped sharing organizations according to their areas of application. Owyang (2013, 2016), for instance, in his first version of the often-cited honeycomb, divided sharing startups into six categories, such as food, space, and services, and later enlarged the honeycomb to include sixteen categories. Other approaches proposed labels such as "car sharing," "community gardening," and "co-working" that reflect sharing model application areas (Botsman and Rogers 2010).

Later approaches took account of organizing practices such as lending, swapping, and sharing, as well as other central supportive organizational characteristics and features (e.g., Cohen and Kietzmann 2014). The purpose of these categorization efforts is to define the sharing economy (e.g., Codagnone and Martens 2016; Puschmann and Alt 2016) and to distinguish the various organizations within the entire sharing field or within segments of the field (e.g., Buttle et al. 2013; Cohen and Kietzmann 2014; Voytenko Palgan et al. 2017). Other categorization approaches draw boundaries between the sharing economy and other fields (e.g., Acquier et al. 2017; Belk 2014; Frenken and Schor 2017; Kenney and Zysman 2016). These approaches are particularly interesting because they-implicitly or explicitly - contribute to debates about which organizational features are legitimate by defining categories of acceptable sharing organizations.

Based on a thorough literature review (Boell and CecezKecmanovic 2014; Hart 2018) of existing categorization approaches (e.g., Frenken and Schor 2017; Voytenko Palgan et al. 2017; Cohen and Muñoz 2016), we conclude that such approaches categorize sharing-economy organizations along one or several of the following (mostly dichotomous) five dimensions. First, referring to characteristics of exchanged products and activities, authors differentiate between physical goods, services, or work when defining or characterizing the sharing economy (e.g., Cohen and Muñoz 2016; Frenken and Schor 2017; Gerwe and Silva 2018). Second, highlighting the relevance of an online platform, some authors exclude offline models such as community gardens and co-working spaces (e.g., Hamari et al. 2016), while others include them (e.g., Cohen and Muñoz 2016). Third, transaction characteristics represent another dimension for categorizing sharing organizations, differentiating between monetary and non-monetary transactions as well as transactions involving access over ownership versus transfer of ownership (e.g., Belk 2014; Schor 2014; Voytenko Palgan et al. 2017). The fourth dimension refers to the regional scope of organizations. Some authors emphasize the local nature of sharing, thus criticizing and excluding globally active - in particular for-profit-platforms from their definitions and categorizations (e.g., Belk 2014; Gorenflo 2015; Malhotra and Van Alstyne 2014; Rinne 2018). The fifth and final dimension of categorization classifies organizations as belonging to the sharing economy according to the types of interaction partners involved. In particular, discussions circle around the question of whether or not the sharing economy focuses on peer-to-peer models or involves business-tocustomer models as well (e.g., Cohen and Kietzmann 2014; Frenken and Schor 2017; Hamari et al. 2016).

Table 2 provides an overview of how selected literature characterizes the sharing economy referring to these five dimensions. The table aids in comparing existing understandings of the sharing economy and identifying features that are particularly debated as to whether or not they are legitimate. Overall, the table supports recent work suggesting that there is no shared understanding of the sharing economy and categories within it (Kornberger et al. 2018; Mair and Reischauer 2017). Instead, the observed variety provides sharing organizations with a wide degree of latitude in designing and designating themselves as sharing organizations. They may choose among alternatives for features such as "transfer of ownership or no transfer," "monetary compensation for transactions or no monetary compensation," "peer-to-peer or business-to-customer," "online technology-driven or offline," and "locally bound or countrywide/globally active." The continued disagreement 
Table 2 Summary of selected literature categorizing sharing organizations according to six dimensions

\begin{tabular}{|c|c|c|c|c|c|c|c|c|c|c|c|c|}
\hline \multirow[b]{3}{*}{ Reference } & \multicolumn{12}{|c|}{ Dimensions debated in categorization efforts } \\
\hline & \multicolumn{2}{|c|}{\begin{tabular}{|c|} 
characteristics of \\
exchanged products and \\
activities
\end{tabular}} & \multicolumn{2}{|c|}{$\begin{array}{l}\text { relevance of an online } \\
\text { platform }\end{array}$} & \multicolumn{4}{|c|}{ transaction characteristics } & \multicolumn{2}{|c|}{$\begin{array}{l}\text { regional scope of } \\
\text { organizations }\end{array}$} & \multicolumn{2}{|c|}{$\begin{array}{l}\text { types of interaction } \\
\text { partners }\end{array}$} \\
\hline & $\begin{array}{l}\text { tangible } \\
\text { products }\end{array}$ & $\begin{array}{c}\text { services/ } \\
\text { non- } \\
\text { tangible }\end{array}$ & $\begin{array}{l}\text { online- } \\
\text { models }\end{array}$ & $\begin{array}{l}\text { offline- } \\
\text { models }\end{array}$ & $\begin{array}{c}\text { no transfer } \\
\text { of owner- } \\
\text { ship }\end{array}$ & \begin{tabular}{|c|}
$\begin{array}{c}\text { exchange } \\
\text { of } \\
\text { ownership }\end{array}$ \\
\end{tabular} & $\begin{array}{c}\text { non- } \\
\text { monetary }\end{array}$ & monetary & $\begin{array}{l}\text { locally } \\
\text { bound }\end{array}$ & $\begin{array}{l}\text { globally } \\
\text { active }\end{array}$ & $\begin{array}{c}\text { peer-to- } \\
\text { peer }\end{array}$ & $\begin{array}{l}\text { business-to- } \\
\text { customer }\end{array}$ \\
\hline \multicolumn{13}{|c|}{ Botsman and Rogers, 2010} \\
\hline \multicolumn{13}{|c|}{ Frenken and Schor, 2017} \\
\hline \multicolumn{13}{|c|}{ Voytenko et al., 2017} \\
\hline \multicolumn{13}{|c|}{ Cohen and Kietzmann, 2014} \\
\hline \multicolumn{13}{|c|}{ Gerwe and Silva, 2018} \\
\hline \multicolumn{13}{|c|}{ Codagnone and Martens, 2016} \\
\hline \multicolumn{13}{|l|}{ Schor, 2014} \\
\hline \multicolumn{13}{|c|}{ Kenney and Zysman, 2016} \\
\hline \multicolumn{13}{|c|}{ Cohen and Muñoz, 2016} \\
\hline \multicolumn{13}{|l|}{ Hamari et al., 2016} \\
\hline Belk, 2010,2014a & & & & & & & & & & & & \\
\hline
\end{tabular}

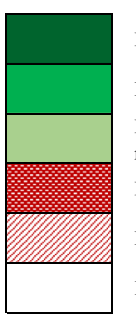

Feature is used in provided definitions and categorizations. It is thus emphasized as a key feature characterizing sharing orgainzations.

Feature is explicitly discussed as characterizing sharing organizations.

Feature is not named as an inclusion criteria, but from the authors' argumentation or based on provided examples of sharing organizations, it becomes clear, that it is a relevant feature of sharing organizations. In some cases, this color is used when authors suggest that a features is an inclusion criteria, but only under certain

Feature is explicitly discussed as an exclusion criteria

Feature is NOT charateristic for sharing organizations. This conclusion can be drawn from the author's argumentation.

Indicates that authors do not discuss this element nor do they provide examples indicating whether it is relevant for them or not. about which business model features of organizations are legitimate and which features are illegitimate indicates that the debates about categories and the legitimacy of specific features are far from being resolved on the field level.

\section{Positioning of Sharing Organizations via Self-Representation}

The continued debates about what purpose the sharing economy should serve, which social, ecological, and economic values sharing organizations should pursue, and which features of sharing organizations are legitimate create an environment for new organizations with many possibilities. In principle, organizations can choose from a wide variety of value propositions to contribute to the purpose of the sharing economy and from quite different organizational characteristics to create and explain their organizational models.

This variety of options might be beneficial for entrepreneurial activities and even for radical innovations (Padgett and Powell 2012). However, this variety comes with the potential disadvantage of a lack of stable categories. Entrepreneurs cannot easily draw upon established categories as blueprints for designing their organizations in a way that has good chances of being recognized and legitimized. Unlike organizations in established fields, organizations in the sharing economy cannot claim to be part of an already understood and accepted organizational category by exhibiting the features of that category (Hsu and Hannan 2005). Instead, they have to explain the position they want to take in the emerging sharing field publicly based on their value propositions and organizational features. While recent work analyzing media debates on the sharing economy exists, and identifies major themes and perspectives on the sharing economy (Cheng 2016; Cheng et al. 2016; Martin 2016), there have been few attempts to systematically analyze organizations' positions in these debates.

To explicate and explain their positions, organizations can present themselves in the media by controlling the publicly available information they choose to reveal (Goffman 1959). In the last two decades, for example, organizational websites have become central interfaces that organizations use to interact with key stakeholders (Powell et al. 2016). Organizations use their websites to take part in classification processes of interaction partners and embed themselves into a field of organizations with different forms (Powell and Oberg 2017). Whether the information these organizations provide about themselves reflects true aspects of organizational identity (Scott and Lane 2000) or whether it is a symbolic adoption to environmental expectations (Fiss and Zajac 2006; Westphal and Zajac 1998) is difficult for outside observers to decide. Independent of the accuracy or truth of these self-representations, the publicly available information about sharing organizations' positions is part of the debates and thus contributes to the social 
construction of meaning in the sharing economy (Berger and Luckmann 1991; Green 2004; Phillips et al. 2004).

The question of how sharing organizations position themselves vis-à-vis existing debates through their self-representation brings forth three particularly interesting issues worth investigating:

First, identifying which values sharing-economy organizations claim to promote to gain recognition as good sharing organizations is important. More specifically, do they promote social, ecological, or economic values, or combinations of these values? Organizations often claim to promote values that reflect environmental expectations in their mission statements (Bartkus and Glassman 2008; Peyrefitte and David 2006). Additionally, they use keywords that mark specific value propositions throughout their texts.

The second issue with self-representation is uncovering which features of their organizational models sharing-economy organizations communicate and emphasize to present themselves as having the right model. More specifically, which organizational features of their business models do they highlight when they describe how they create and capture value? To attract and to interact with stakeholders-especially with participants who want to share something - sharing organizations explain certain aspects of their business models.

The third important issue is to understand how sharing organizations link features and values. If certain features are repeatedly used in combination with particular promoted values, this regularity might help to legitimate organizations which apply this combination. To uncover such legitimation strategies, we ask: How are value propositions and business model features linked in the self-representation of sharingeconomy organizations?

\section{Data and Methods}

To study how sharing organizations present themselves via value propositions and business model features on the Internet, we conducted an explorative study with the three phases of case selection, coding, and analysis. As this is (to the best of our knowledge) the first study that analyzes value propositions and features systematically, we combined established methods for specific steps in an innovative way.

\section{Case Selection: Prototypical Organizations of Sharing-Economy Application Areas}

As we are interested in the reactions of the vast heterogeneity of sharing organizations toward societal expectations, our case selection process aims to identify prototypical organizations of different sharing-economy areas. We started with the identification of application areas and then searched for prototypical organizations for each of these areas.

\section{Application Areas}

To identify application areas, we turned to academic publications about the sharing economy, which mention different areas of application. We searched for publications (articles and books) using the keywords "sharing economy," "share economy," "shareconomy" and German translations (e.g., "Ökonomie des Teilens") in Google Scholar in November and December 2016. Reading abstracts allowed us to decide if publications represented relevant contributions to the sharing-economy debate. We based our decisions on the broad definition by Botsman and Rogers' (2010) and Botsman's (2013) studies, including "economic model(s) based on sharing, swapping, trading, or renting products and services, enabling access over ownership." We compiled a ranking of publications ordered by the number of citations they received. Starting with the most cited publication, we read the texts in detail, collected all labels that referred to application areas, and grouped synonymous labels together into areas such as "car sharing," "co-working," "community gardening," "accommodation platforms," etc. After reading around 600 pages of text from the first 11 publications, we did not find additional areas in the next nine publications. To make sure that we had actually reached saturation, we randomly picked ten references from the remaining list of 80 publications to look for additional labels and did not find any. In this process, we identified 20 different areas of application, thereby including both online and offline models.

\section{Prototypical Organizations}

For each application area, we wanted to identify prototypical organizations. These are those organizations that are repeatedly mentioned in public debates as representative examples of a specific application area. We decided to select Germany as the location for our sampling because important actors on the national level (ministries, weekly newspapers, business associations, etc.) currently discuss different sharing models and their potential social, ecological, and economic impacts. After evaluating different databases, we settled on Factiva as the best source to cover German debates via press articles and limited our search to the highest-circulating national current-affairs newspapers and magazines in Germany (17 sources including online and print versions). To identify articles covering specific areas of application, we searched for "sharing economy" (and its variations) combined with the main label for each of the 20 application areas (and its synonyms and German translations). Our search yielded 368 articles (840 pages). Then, we collected the names of 
Table 3 Selection of organizations in the sample (full list available from the authors on request)

\begin{tabular}{ll}
\hline Name of sharing organization & Application area \\
\hline Car2go & Carsharing \\
BlaBlaCar & Ridesharing \\
Call A Bike & Bikesharing \\
Uber & Chauffeur/Ride service \\
AirBnB & Lodging/Flat-Sharing \\
Betahaus Berlin & Coworking Space \\
Kleiderkreisel & Second Hand Platform \\
Leihdirwas & Sharing/Renting/Lending Platform \\
Wir.de & Community/Neigborhood Services \\
Spotify & Communication/Social Media/Entertainment \\
99designs & Job Placement/Crowdsourcing \\
Foodsharing & Foodsharing \\
Wikipedia & Knowledge Sharing/Open Source \\
Startnext & P2P-Lending/Crowdfunding/Finance \\
Skillharbour & Time Bank/Skillshare/Bartering \\
Gemeinschaftswerkstatt Die Werke & Fablab/Repair Shop/Tech Shop \\
Prinzessinnengaerten & Community Gardening/Landshare/CSA \\
Unser Parkplatz & Parking Sharing \\
Freifunk.net & Infrastructure/Utilities \\
Tauschgnom & Swapping Platform \\
\hline
\end{tabular}

organizations mentioned as examples in these texts. For some application areas, articles mentioned two types of exemplary organizations: one organization employing an old model of organizing shared use (for instance, the car rental provider Hertz) and one organization exemplifying a new model (for instance, the free-floating car sharing provider Car2Go). We decided not to delete the examples of older models from our list of prototypical organizations. During the analyses, we did robustness checks with and without these examples of older models. In this paper, we will focus on those results that are stable across robustness checks. We arrived at a list of 62 organizations repeatedly mentioned as examples of sharing organizations in public debates about the sharing economy in Germany (see Table 3).

\section{Coding of Features and Value Propositions of Organizations}

To collect data on features and value propositions for each organization in the sample, we apply a theoretically informed inductive approach (Mayring 2014) to code the organizations' websites.

\section{Coding Scheme}

Following an approach that distinguishes substantive codes and theoretically informed codes (Holton 2007), we developed a coding scheme with two levels of codes: first-level codes capture website content, and second-level codes aggregate these substantive codes based on theoretical concepts.

\section{Value Propositions and Values}

Value propositions capture what values organizations promise their target groups (Lepak et al. 2007; Yunus et al. 2010). To learn what value propositions sharing organizations potentially refer to, we consulted texts analyzed during our literature review (e.g., Belk 2014; Botsman and Rogers 2010; Martin 2016; Schor 2017; Sundararajan 2014). To identify actual value propositions, we read the organizations' mission statements (for instance, on the front page or on the "about us" page). We found many descriptions of value propositions and coded them as first-level codes. Finally, we grouped the first-level codes into three second-level codes for "social value," "ecological value," and "economic value."

\section{Organizational Features and Business Model Elements}

Features are publicly visible organizing practices or elements of organizational structure and describe how organizations create and capture value (Lepak et al. 2007; Yunus et al. 2010). To get an initial understanding of potential features in the sharing economy, we analyzed existing business model frameworks in recent literature on sustainable business models that have already been applied to describe business models in the sharing economy (Boons and 
Lüdeke-Freund 2013; Cohen and Kietzmann 2014). This work and the literature discussed in the theory part of this paper (for instance: Belk 2014; Cohen and Kietzmann 2014; Frenken and Schor 2017; Schor 2017; Voytenko et al. 2017) provide more or less detailed descriptions of organizational activities that pointed us to features of business models in the sharing economy (Massa et al. 2017). Organizations describe these features when they explain their products and services, explicate how they interact with users, community members and customers, and in the terms and conditions sections on their websites-thereby using different terminologies and narratives than can be found in academic literature. Other features can be identified by analyzing forms and functions of the websites. For instance, on one website we found the statement "All our neighbors can login here," which signals a regional scope (users are called neighbors) and an online community tool (login function for users). To capture such information, we developed the three codes "community management," "registration required," and "regional scope." We grouped first-level codes into seven second-level codes that reflect elements of sharing organizations' business models: "roles and activities," "organizing practices," "coordination and control mechanisms," "access and channels," "income source," "pricing mechanism," and "product characteristics." Second-level codes were developed bottom-up and informed by existing business model frameworks (Boons and Lüdeke-Freund 2013).

\section{Coding Process}

To develop the coding scheme, the authors started with a random sample of 20 organizations and inductively coded value propositions and features at the first level (Holton 2007). We then went back and forth between the two levels of codes: We looked for first-level codes on the websites and assigned second-level theoretical concepts to them, and vice versa. The resulting coding scheme entails 30 firstlevel codes for value propositions and 63 first-level codes for features, including descriptions of the codes (see list in Tables 4, 5). To code all organizations, a team of two authors and three student assistants discussed the coding scheme in detail and tested it on five randomly selected cases from the sample. Then two coders from the team of five decided independently for each organization whether it should be assigned a code (binary coding of value propositions and features). If there were coding differences, the coders discussed coding decisions in the group until they reached agreement. We refined descriptions of first- and second-level codes in order to make sure that codes were clearly specified.

\section{Data Analysis: Networks of Features and Linkages to Values}

Interested in the overall positioning of sharing-economy organizations in light of debates about organizational characteristics and the purpose of the sharing economy, we start with an analysis of typical combinations of features, proceed with the relevance of features for specific value propositions, and finally look at linkages between features and values on an aggregated level.

\section{Network of Features}

Our coding captures the set of features characterizing each prototypical sharing organization in our sample. As we are interested in whether we can identify patterns of combining features across sharing organizations, we aggregated all individual sets of features. We created a semantic network (Carley and Kaufer 1993; Carley and Palmquist 1992; Leydesdorff and Vaughan 2006) consisting of nodes that represent features and relationships capturing the number of co-occurrences of features in the organizational sample (Distel 2010; Wasserman and Faust 1994). To be able to depict particularities of organizations, we added nodes indicating the absence of a feature that is otherwise observable among many individual sets of features. For instance, we added a node for "no registration required" because most organizations required their community members to register.

To interpret the resulting network of features, we created network visualizations. In the network figures presented in this paper, we selected the five strongest relationships for each feature and removed all others. Then we applied the Fruchterman-Reingold algorithm (Fruchterman and Reingold 1991), which positions nodes closely together that often co-occur and are thus strongly connected. As a result, structures in networks-for instance, densely connected clusters of features-and differences between core and peripheral features became visible.

To get a better understanding of the differences of clusters, we selected those sets of relationships with local maxima of weights as the core of a cluster. These relationships connect features that repeatedly appear in combination on sharing organizations' websites. One can assume that stakeholders and observers recognize these features because of their repetition across several areas of application. In addition, we created areas around each core by adding those features that are neighbors to the core and that do not lie in the middle between cores. We repeated this process until all features that met these requirements were assigned to a cluster. We interpret features that were added in this process as peripheral features. 
Table 4 List of first- and second-level codes for value propositions

$\mathrm{Nr}$ First-level codes for value propositions Long title of first-level code

Second-level Codes for value proposi-

tions

\begin{tabular}{|c|c|c|c|}
\hline 1 & Protect environment & Contribute to protection of the environment & Ecological \\
\hline 2 & Intensify use & Intensify use of products, spaces or assets & Ecological \\
\hline 3 & Reduce emission & Reduce emissions (may refer to any kinds of emissions) & Ecological \\
\hline 4 & Extend lifecycle & Extend the lifecycle of products, spaces, assets & Ecological \\
\hline 5 & Reduce waste & Contribute to reduce waste. & Ecological \\
\hline 6 & Access to resources & $\begin{array}{l}\text { Enable or enhance access to resources of any kind (products, spaces, ser- } \\
\text { vices, assets); described in economic terms }\end{array}$ & Economic \\
\hline 7 & Save money for consumers & Enable users of organization to save money & Economic \\
\hline 8 & Make money for providers & Provide income sources for providers of services or products & Economic \\
\hline 9 & Offer additional services & Offer additional, new services (that have potentially not existed before) & Economic \\
\hline 10 & Offer high-quality products & $\begin{array}{l}\text { Ensure a high quality of provided services and products; make high-quality } \\
\text { products available }\end{array}$ & Economic \\
\hline 11 & Save time for users & Save time for users through offered services & Economic \\
\hline 12 & Reliable accessability to product & $\begin{array}{l}\text { Make sure that products, spaces, services, assets can be reliably (whenever } \\
\text { needed) accessed; aspect of reliability is highlighted }\end{array}$ & Economic \\
\hline 13 & Overcome cost-quality tradeoff & Overcome cost-quality tradeoff & Economic \\
\hline 14 & Generate additional income & Users of organization are enabled to generate additional income & Economic \\
\hline 15 & Increase quality of products & Higher quality of products is provided or the ability to increase quality & Economic \\
\hline 16 & Flexibility and choice & Increase the flexibility for consumers or the number of (product) choices & Economic \\
\hline 17 & Increased mobility for users & Increase the mobility of users & Economic \\
\hline 18 & Substitute market & $\begin{array}{l}\text { Provided service/product are described as substitutes for an existing service/ } \\
\text { product }\end{array}$ & Economic \\
\hline 19 & Alternative solutions & $\begin{array}{l}\text { Provide alternative solutions to existing ones that are provided by the organi- } \\
\text { zation for users }\end{array}$ & Economic \\
\hline 20 & Increase of social interaction & Increase of number or intensity of social interactions & Social \\
\hline 21 & User experience & Provide a good user experience; user experience is highlighted & Social \\
\hline 22 & Access to community & $\begin{array}{l}\text { Enable access to a community/provide users with access to community; } \\
\text { focus on access }\end{array}$ & Social \\
\hline 23 & General community & Create or maintain community, without specifying the community & Social \\
\hline 24 & Local community & $\begin{array}{l}\text { Create or maintain community, thereby specifying the community as a local } \\
\text { community. }\end{array}$ & Social \\
\hline 25 & Neighborhood community & $\begin{array}{l}\text { Create or maintain community, thereby specifying the community as com- } \\
\text { munity within the neighborhood/of neighbors }\end{array}$ & Social \\
\hline 26 & Trust in community & Enhance general trust towards community/the concept of community & Social \\
\hline 27 & Accessability to product & $\begin{array}{l}\text { Increase accessability to product or service; described in social terms } \\
\text { (access to so far not-accessible products /services) }\end{array}$ & Social \\
\hline 28 & Social inclusion & $\begin{array}{l}\text { Enhance social inclusion (can be within collunity, neighborhood, society } \\
\text { etc.) }\end{array}$ & Social \\
\hline 29 & Community building & Contribute to community building/to the development of a community & Social \\
\hline 30 & Neighborhood care & Enhance neighborhood care or social cohesion in neighborhoods & Social \\
\hline
\end{tabular}

\section{Relevance of Features for Value Propositions}

As a first step toward understanding how sharing organizations combine features with values, we evaluate the relevance of features for individual value propositions. To do so, we counted how many organizations claimed to support each value proposition. Then, for each feature, we counted how often it was present in these organizations and divided this number by the number of organizations that claimed to support the respective value proposition. The result is a vector for each value proposition that captures the relevance of features. Visualizing these vectors in the network of features helps interpret which features appear often in organizations that promote a specific value proposition. For that matter, the color and size of nodes indicate the relevance of each feature. 


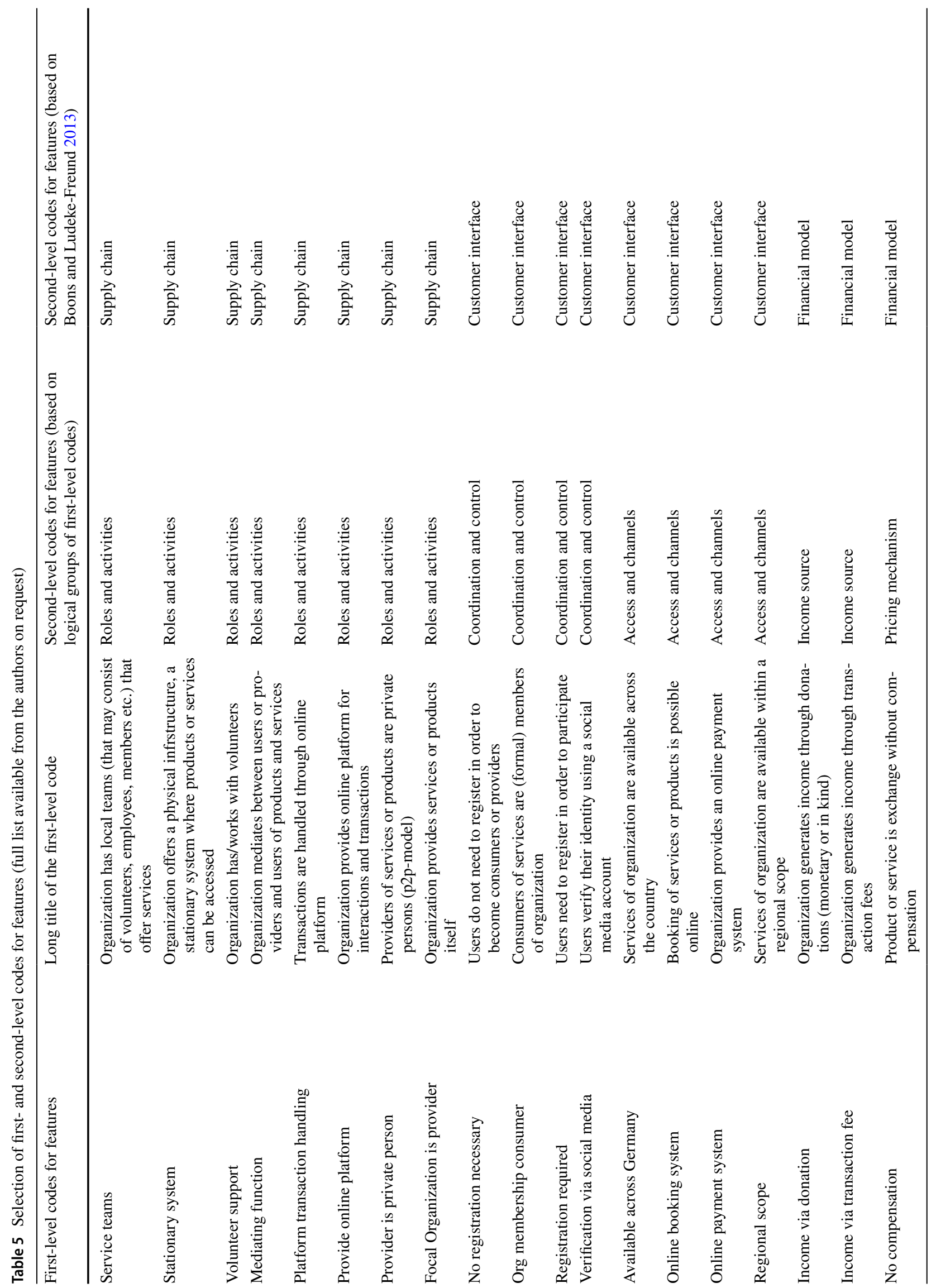




\section{Linkages Between Features and Values}

After analyzing the relevance of features for specific value propositions, we turned to an aggregated assessment of the linkages between features and values. We summarized the previously computed vectors for specific value propositions according to their belonging to social, ecological, and economic values, created a sum of all vectors, and computed the percentage of each value for each feature. This resulted in a triad of percentages for social, ecological, and economic values for each feature, which we call "feature-values linkage" because it captures to what extent a feature is relevant for a group of value propositions. Three types of feature-values linkages are of specific interest in our analysis: First, a high percentage of one value-for example, the group of social value propositions-indicates that the respective feature is primarily mentioned in self-representations of organizations that address social values. Such feature-value linkages with one predominant value are marked as B (business/economic), S (social), or E (ecological) and colored blue, red, or green, respectively, in tables and figures. Second, if two values have higher percentages than the third, the feature is used by organizations that address two values-for example, in socially-ecologically oriented organizations-or the feature is used in two sets of organizations that propose either one or the other value. We represent these types of linkages with the combined labels $\mathrm{B}+\mathrm{S}$ (business and social), $\mathrm{B}+\mathrm{E}$ (business and ecological), and $\mathrm{S}+\mathrm{E}$ (social and ecological) and mixed colors (light blue, light green, or light brown). Third, when all three values have relatively similar percentages, the linkage between feature and values follows no clear pattern. These cases are labeled $\mathrm{B}+\mathrm{S}+\mathrm{E}$ (business, social, and ecological) and colored in dark brown. To visualize the results of this step, we colored the nodes in the network of features according to their primarily addressed values or their type of mixed values. The resulting figure helps us to interpret the linkage between features and values made by the self-representations of sharing organizations.

\section{Findings}

Below, we start with the network of features of prototypical sharing organizations in Germany, proceed with the relevance of features for specific value propositions, and finally, present the linkages between features and values on an aggregated level.

\section{Network of Features}

The network of features (see Fig. 1) shows an interesting structure, with two clusters of densely connected featuresone in the lower and one in the upper part of the visualization-and a bridge of connecting features on the right side.

That two clusters become visible is surprising for those who expect some common features of sharing organizations in their self-representations. If sharing organizations shared many features, we would observe a center-periphery structure with shared features in the center of the network and peripheral features representing variations of the shared organizational characteristics. Instead, we observe two clusters of features.

To get a better understanding of the differences between the two clusters, we identified two local maxima of sets of relationships with strong connections-one in each cluster-and interpreted them as the cores of the clusters. To highlight the differences between core and peripheral features in each of the clusters, we created borders around neighboring features that could be assigned clearly to one of the two clusters (see Fig. 2). The marked areas highlight two distinct clusters with core and peripheral features with a distance of one or two steps from each core. We interpret the combination of core and peripheral features as categories because of their repeated joined occurrence in prototypical organizations.

Core features are essential for each respective category, while the peripheral features are optional: To mark their belonging to a category, organizations reflect the core features in their self-representations, while peripheral features can be substituted among each other or even left out. The configuration of peripheral features marks the variability of a category in two ways: First, the higher the number of peripheral features in a category, the higher the variability of this category. An example of this variability is the cluster on the bottom which has many interchangeable features. Second, the higher the distance of features from the core, the higher the variability. An example is the cluster on the top, which has peripheral features two steps away from the core. These features are not essential for organizations of this category, but organizations that have these features share core features with other organizations of the same category.

\section{Category of Grassroots Initiatives}

The first category located in the upper part of the network has two core features: "service team" and "stationary system." Organizations of this category have a core group of people ("service team"), who establish and maintain a physical infrastructure ("stationary system") that users access to use, exchange, or share products and services. As both 


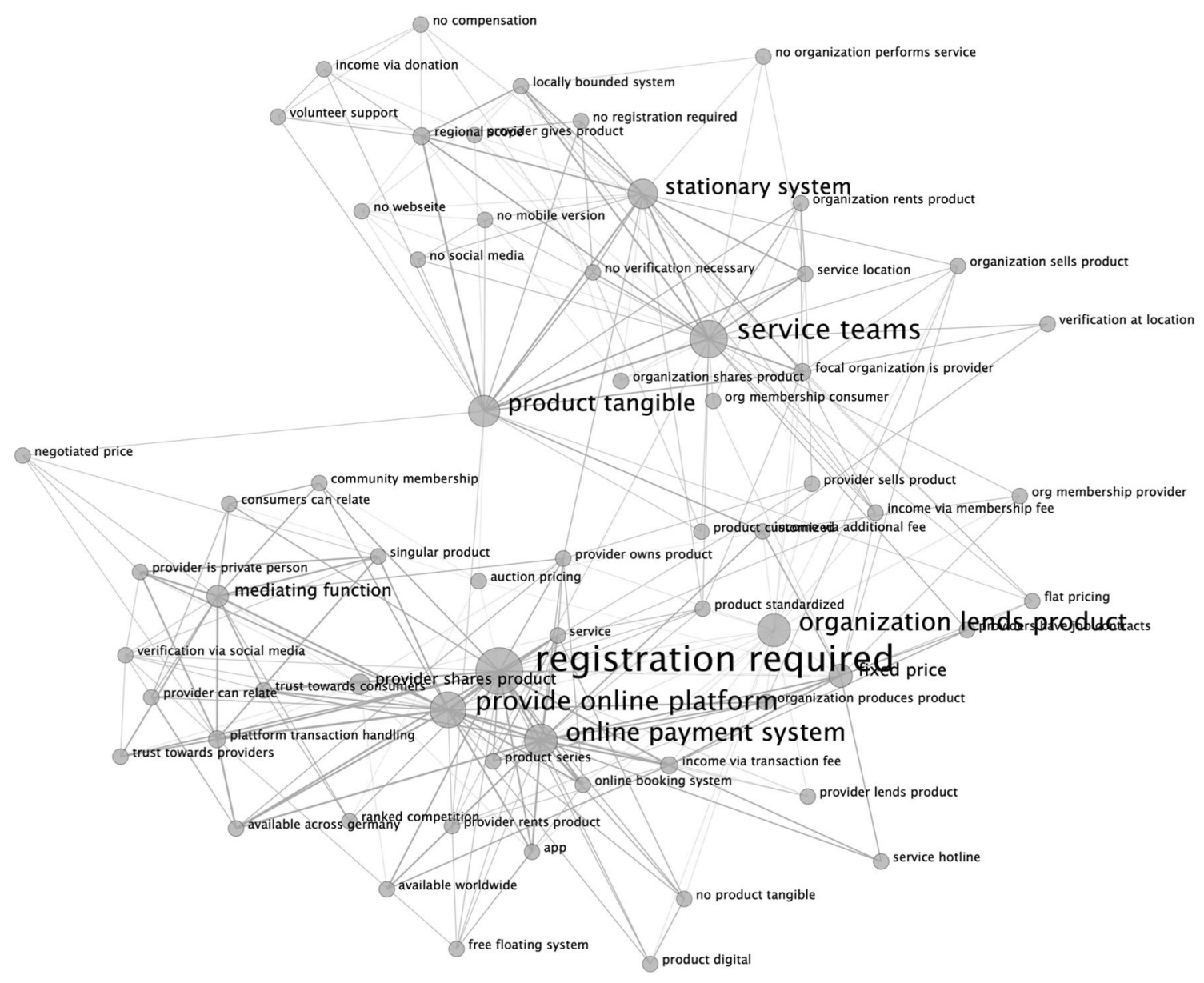

Fig. 1 Co-occurrence of features. Nodes: features. Relationships: main co-occurrences for each feature. Positioning: Fruchterman-Reingold. High-resolution figures are available online at https://www.i-share-economy.org/goodandright

features characterize grassroots initiatives in an abstract way, we accordingly call this category "grassroots initiatives."

The core features are surrounded by features that describe where an initiative's services can be accessed, roles and activities of members, the role of the initiatives in transactions, and their income sources and pricing mechanisms. We observe that grassroots initiatives have a physical infrastructure where people can get information about the organization and learn about how they can participate. Grassroots initiatives thereby target potential members, users and customers in the city or neighborhood they are located in ("regional scope"). Interested visitors can enter the initiatives' premises and get into contact with the initiatives' members without becoming formal members themselves ("no registration necessary"), but when they consume or use resources, they are expected to become members of the initiative's community ("org membership consumers"). This means that organizations in this category do not typically offer resources to anonymous customers. In transactions with their members, grassroots initiatives take over the role of providers ("focal organization is provider") and offer access to products, spaces, or services-mostly for free ("provider gives product") and without any compensation directly connected to transactions ("no compensation").

Connected at a two-step distance to the core, we find additional features such as "income via donation" and "volunteer support." These features help to understand how initiatives generate necessary inputs to keep their operations running. They strongly rely on volunteers and their work ("volunteer support") or on funding from third parties as donations ("income via donation").

The set of observed features of the grassroots categoryin particular the stationary system, service team, and regional scope features-accords with extant descriptions of sharing-economy organizations that have a local focus. For instance, Martin et al. (2015) define grassroots as groups or networks of activists and organizations that develop solutions (oftentimes novel, innovative ones) with and for local communities. Light and Miskelly (2015) define the category of local sharing initiatives-including community gardens, 


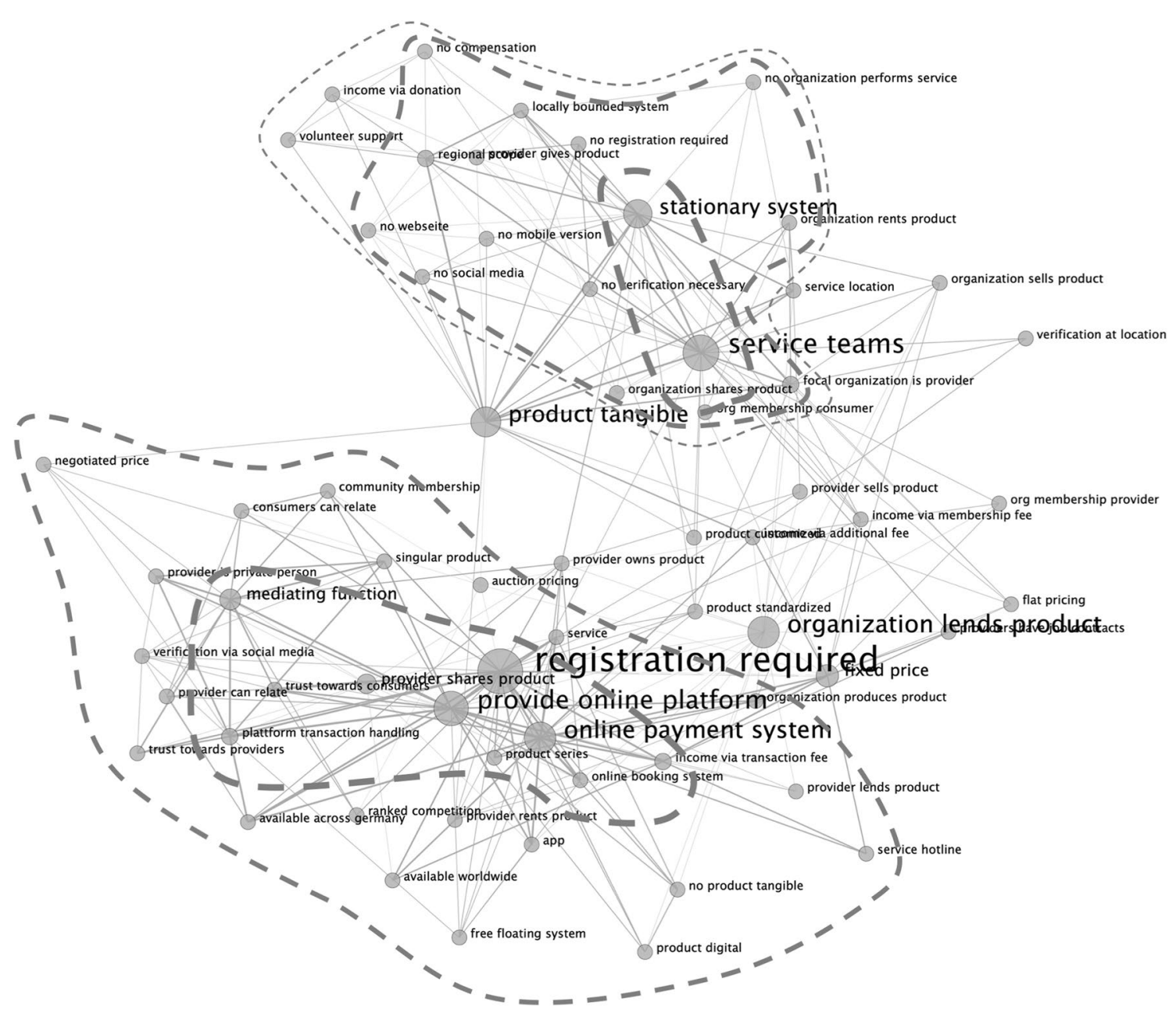

Fig. 2 Core and peripheral features of the two categories. Nodes: features. Relationships: main co-occurrences for each feature. Borders: core $=$ thick dotted line; periphery distance $1=$ medium dotted line; periphery distance $2=$ thin dotted line. Positioning: Fruchterman-Reingold

repair shops, micro-libraries, and time banks—as "endeavors to build space $[\ldots]$ where people come together[,] thus enhancing the community" (ibid., 55). Our observation that the grassroots category has a stationary system as a core feature fits well with Cohen and Muñoz's (2016) work on the role of the sharing economy in accelerating sustainable consumption and production patterns in cities. Many of the organizations that fall into our grassroots category-community gardens, repair cafés, co-working spaces, and foodsharing initiatives-also fall into two quadrants of Cohen and Muñoz's (2016) typology, which the authors call "localized sustainable consumption" and "localized sustainable production."

\section{Category of Platform-Based Organizations}

The second category located in the lower part of the network has seven core features: "provide online platform," "registration required," "mediating function," "platform transaction handling," "online booking system," "online payment system," and "income via transaction fee." Organizations of this category provide an online platform for users ("provide online platform"). They require their users-community members and customers - to register before gaining access to the provided products or services ("registration required"). Their role in transactions is to mediate between product and service providers and customers ("mediating function"). To fulfill this role, they rely on two softwarebased systems: one to initiate the transaction ("online booking system") and one to finalize the transaction by securing the payment ("online payment system"). The organizations generate income via transaction fees ("income via transaction fee"). Taken together, these seven features describe platform-based organizations in an abstract but detailed way. Therefore, we label this cluster of features "platform-based organizations." 
The core features are surrounded by other features that capture detailed organizational characteristics such as the scope of the organization, the role of members, mechanisms to create trust, and pricing mechanisms. Organizations of this category are active across Germany ("available across Germany") or even worldwide ("available worldwide"). They make this possible via their online platforms, which are supported by mobile apps ("app") and customer service hotlines ("service hotline"). These various channels facilitate interactions between providers and consumers of products and services ("providers can relate" and "consumers can relate"). Additionally, the organizations employ practices designed to enhance trust between providers and customers ("trust toward providers" and "trust toward consumers"). Building trust is especially important for providers of products and services, as these are private individuals ("provider is a private person") who participate in a peer-topeer exchange with customers. One often used mechanism to signal trustworthiness of community members is verification via another social media platform ("verification via social media"). Because organizations of these categories are mediators that coordinate transactions, alternative pricing mechanisms-such as "fixed pricing," "negotiated pricing," and "auction pricing" - can be employed. The relatively high number of peripheral features reflects the variability of the category which is able to capture both peer-to-peer and business-to-customer models.

The set of features that characterizes the core of the platform category aligns with existing work on digital platforms in the sharing economy (Schor 2014). For instance, Kenney and Zysman (2016) define the platform category as digital infrastructures and frameworks that enable and shape various interactions and transactions among participants. In a similar vein, Hamari et al. (2016) argues that sharingeconomy platforms act as "economical-technological coordination providers" (ibid., p. 4) that enable the exchange of goods and services between peers. The two components (technical infrastructure and organizational elements) of the platform category also resonate with Gawer's (2014) definition of platform organizations. She points to organizational elements of platform organizations for coordinating involved agents and the technical infrastructure of platforms. In the third part of her definition, she emphasizes that platformbased organizations create value by utilizing economies of scale and scope on the supply and demand side. The platform category we identify serves this function because it mediates between users and providers.

The differences between the two categories of grassroots initiatives and platform-based organizations are strikingly obvious in the network figure and on several dimensions of features: local versus nationwide scope, initiatives as providers in transactions versus peer-to-peer transactions, no compensation versus transaction fees.

\section{Relevance of Features for Value Propositions}

Having analyzed the network of features, the next question is what relevance these features have for specific value propositions. To answer this question, we created visualizations for each value proposition in which the relevance of features for the respective value is highlighted. We found two contrasting patterns.

\section{Shared Value Proposition}

As an example of the first pattern, Fig. 3 shows the visualization of the value proposition "intensify use," which addresses the central expectation that the sharing economy contributes to intensifying the use of resources through sharing, lending, or gift giving.

Most nodes in this network are purple, meaning that most features appear in the self-representations of organizations that propose intensifying the use of resources. The size of nodes indicates which percentage of these organizations actually uses the respective features in their self-representations. One can easily observe in the figure that the core features of both categories are highly relevant for such organizations and initiatives. In addition, in each category, one peripheral feature stands out due to the large size of the respective node: "regional scope" in the grassroots category and "available across Germany" in the platform category. This shows that organizations from both categories that want to intensify resource use act locally, in contrast to being active worldwide. The observation that organizations and initiatives of both categories propose to intensify the use of resources agrees with central stakeholder expectations about the sharing economy. Although their approaches to addressing this goal are quite different, organizations from both categories reflect this shared goal in their self-representations. While the previous result of two distinct categories pushed us to question whether grassroots initiatives and platform-based organizations have something in common, this analysis of the relevance of features for specific value propositions shows that organizations from both categories address shared goals.

\section{Category-Specific Value Proposition}

In contrast to the pattern of a shared value proposition, we present the relevance of features for the value proposition "neighborhood care" as an example of the second pattern we observed. In principle, neighborhood care can be performed by grassroots organizations or via online platforms used to organize peer-to-peer support in neighborhoods. In 


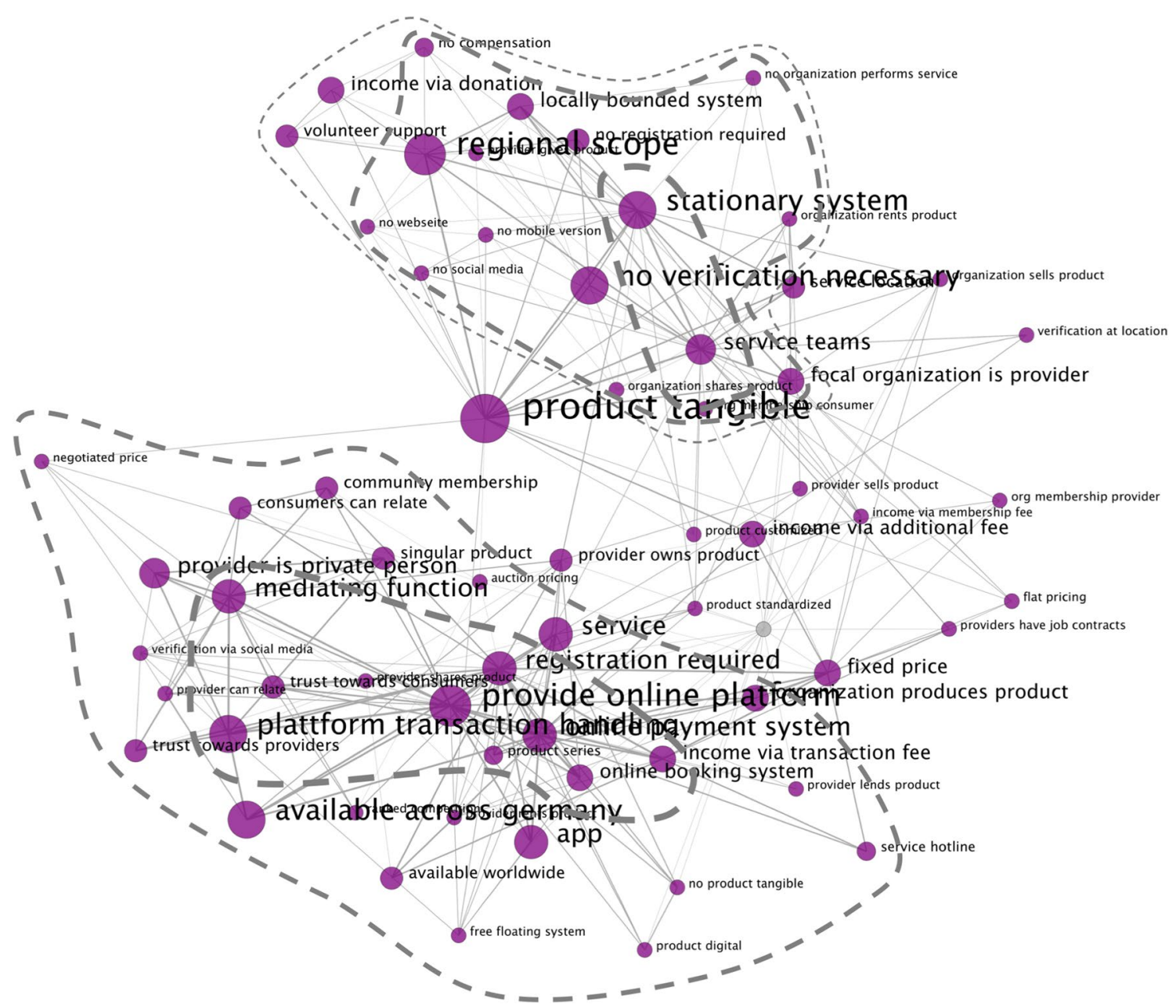

Fig. 3 Relevance of features for value proposition "intensify use." Nodes: features. Size of nodes: relevance of a feature for a the specific value proposition. Color of nodes: purple for relevance $>0.0$; gray $=$ no relevance. Relationships: main co-occurrences for each

reality, we observed a distinct pattern of features repeatedly used by prototypical sharing organizations in Germany that address this purpose (see Fig. 4).

Three observations are striking: First, interconnected features in the grassroots category are highly relevant for addressing neighborhood care, while core features in the platform category have no relevance. Second, the relevance of the peripheral features "volunteer support," "no compensation," and "receive donations" of grassroots initiatives is particularly striking, meaning that sharing initiatives pursuing neighborhood care strongly rely on volunteers and donations. This indicates that the social goal of supporting neighbors is not addressed using approaches based on monetary transactions but using approaches relying on altruism. Third, some features in the periphery of the platform-based category are used when the goal of neighborhood care is addressed. This supports the possibility that platform-based organizations can address this feature. Borders: core $=$ thick dotted line; periphery distance $1=$ medium dotted line; periphery distance $2=$ thin dotted line. Positioning: Fruchterman-Reingold

social goal too, but prototypical organizations in Germany in this category seldom did this at the time of our data collection.

\section{Linkages Between Features and Values}

After observing that some value propositions are shared across categories and that other value propositions are specific to certain categories, we now turn to the question of to what extent features are used by organizations which address social, ecological and economic values.

\section{Value Combinations and Strategies}

To address this question, we computed the feature-value linkages for all features to capture the feature's relevance for social, ecological, and economic values. As described 


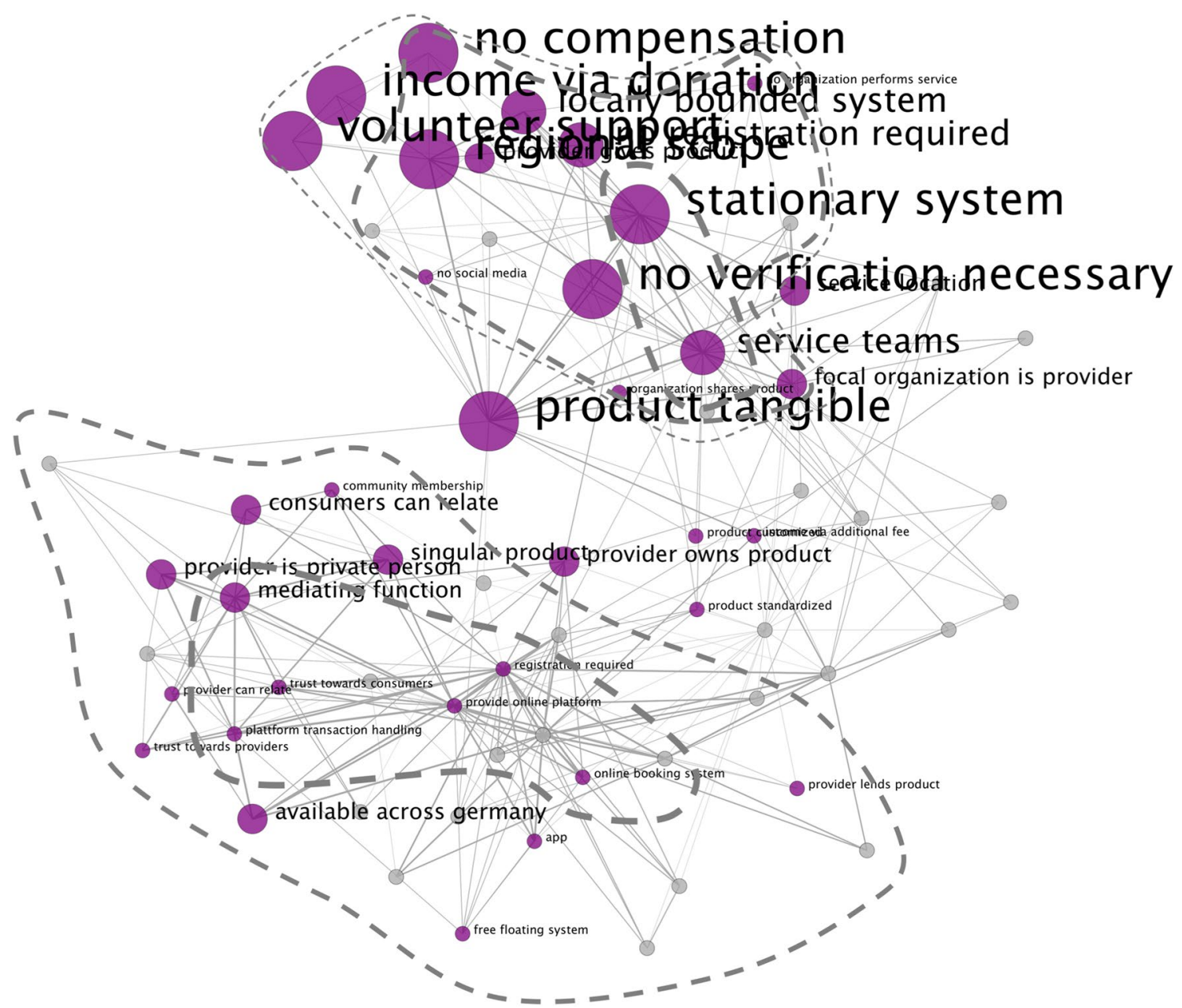

Fig. 4 Relevance of features for value proposition "neighborhood care." Nodes: features. Size of nodes: relevance of a feature for a the specific value proposition. Color of nodes: purple for relevance $>0.0$; gray $=$ no relevance. Relationships: main co-occurrences for

in the methods section, a feature-values link can be in one of seven different states $(\mathrm{B}=$ primarily economic, $\mathrm{S}=$ primarily social, $\mathrm{E}=$ primarily ecological, $\mathrm{B}+\mathrm{S}=$ economic and social, $\mathrm{B}+\mathrm{E}=$ economic and ecological, $\mathrm{S}+\mathrm{E}=$ social and ecological, $\mathrm{B}+\mathrm{S}+\mathrm{E}=$ indifferent). By multiplying these options with the two possibilities of features belonging to the core or periphery of a category, we arrived at 49 different possibilities of combined sets of features and values (see Fig. 5).

If we subsume social and ecological values under the umbrella term "sustainability values," two optional strategies for organizations to combine features and values emerge: Sustainability values can be addressed by core features that are predominantly relevant for social or ecological values (see no. 8-21), that combine social or ecological values with economic values (see no. 22-35), or that combine social and ecological values (see no. 36-42). If several densely each feature. Borders: core $=$ thick dotted line; periphery distance $1=$ medium dotted line; periphery distance $2=$ thin dotted line. Positioning: Fruchterman-Reingold

interconnected core features of a category share sustainability values, we call this strategy "sustainability by model."

A second option of combining features and values is to address sustainability values with peripheral features (no. 1-7 and no. 43-48). Because peripheral features are optional for organizations of a category, so are the values for which these features are relevant. Organizations may or may not employ these features; they may or may not address these values. Therefore, we call this strategy "sustainability by feature." Employing this strategy is easier than implementing the first strategy: Realizing the "sustainability by model" strategy involves linking interconnected core features to sustainability values. In turn, the "sustainability by feature" strategy is fulfilled by just adding relatively independent features with which sustainability values are addressed. 
Fig. 5 Links between central/ peripheral features and values

\begin{tabular}{|c|c|c|c|c|}
\hline & Central & Peripheral & Type & Obs. \\
\hline No. 1 & $\mathrm{~B}$ & B & & $\mathrm{P}$ \\
\hline No. 2 & B & $S$ & $\mathrm{sbf}$ & \\
\hline No. 3 & $\mathrm{~B}$ & E & $\mathrm{sbf}$ & \\
\hline No. 4 & $\mathrm{~B}$ & $\mathrm{~B}+\mathrm{S}$ & $\mathrm{sbf}$ & $\mathrm{P}$ \\
\hline No. 5 & B & $B+E$ & $\mathrm{sbf}$ & \\
\hline No. 6 & B & $\mathrm{S}+\mathrm{E}$ & $\mathrm{sbf}$ & \\
\hline No. 7 & B & $\mathrm{B}+\mathrm{S}+\mathrm{E}$ & & $\mathrm{P}$ \\
\hline No. 8 & S & B & sbm & \\
\hline No. 9 & S & S & sbm & G \\
\hline No. 10 & S & $\mathrm{E}$ & sbm & G \\
\hline No. 11 & S & $\mathrm{B}+\mathrm{S}$ & sbm & \\
\hline No. 12 & $\mathrm{~S}$ & $B+E$ & sbm & \\
\hline No. 13 & $\mathrm{~S}$ & $\mathrm{~S}+\mathrm{E}$ & sbm & $\mathrm{G}$ \\
\hline No. 14 & S & $\mathrm{B}+\mathrm{S}+\mathrm{E}$ & sbm & \\
\hline No. 15 & $\mathrm{E}$ & B & sbm & \\
\hline No. 16 & $\mathrm{E}$ & S & $\mathrm{sbm}$ & \\
\hline No. 17 & $\mathrm{E}$ & E & $\mathrm{sbm}$ & \\
\hline No. 18 & $\mathrm{E}$ & $\mathrm{B}+\mathrm{S}$ & sbm & \\
\hline No. 19 & E & $B+E$ & sbm & \\
\hline No. 20 & $\mathrm{E}$ & $\mathrm{S}+\mathrm{E}$ & $\mathrm{sbm}$ & \\
\hline No. 21 & E & $\mathrm{B}+\mathrm{S}+\mathrm{E}$ & sbm & \\
\hline
\end{tabular}

\begin{tabular}{|c|c|c|c|}
\hline & Central & Peripheral & Type Obs. \\
\hline No. 22 & $\mathrm{~B}+\mathrm{S}$ & B & sbm \\
\hline No. 23 & $\mathrm{~B}+\mathrm{S}$ & S & $\mathrm{sbm}$ \\
\hline No. 24 & $\mathrm{~B}+\mathrm{S}$ & E & sbm \\
\hline No. 25 & $\mathrm{~B}+\mathrm{S}$ & $\mathrm{B}+\mathrm{S}$ & sbm \\
\hline No. 26 & $\mathrm{~B}+\mathrm{S}$ & $\mathrm{B}+\mathrm{E}$ & sbm \\
\hline No. 27 & $\mathrm{~B}+\mathrm{S}$ & $\mathrm{S}+\mathrm{E}$ & sbm \\
\hline No. 28 & $\mathrm{~B}+\mathrm{S}$ & $\mathrm{B}+\mathrm{S}+\mathrm{E}$ & $\mathrm{sbm}$ \\
\hline No. 29 & $\mathrm{~B}+\mathrm{E}$ & B & sbm \\
\hline No. 30 & $B+E$ & $S$ & sbm \\
\hline No. 31 & $B+E$ & E & $\mathrm{sbm}$ \\
\hline No. 32 & $\mathrm{~B}+\mathrm{E}$ & $\mathrm{B}+\mathrm{S}$ & sbm \\
\hline No. 33 & $\mathrm{~B}+\mathrm{E}$ & $\mathrm{B}+\mathrm{E}$ & sbm \\
\hline No. 34 & $\mathrm{~B}+\mathrm{E}$ & $\mathrm{S}+\mathrm{E}$ & $\mathrm{sbm}$ \\
\hline No. 35 & $\mathrm{~B}+\mathrm{E}$ & $\mathrm{B}+\mathrm{S}+\mathrm{E}$ & $\mathrm{sbm}$ \\
\hline No. 36 & $\mathrm{~S}+\mathrm{E}$ & $\mathrm{B}$ & $\mathrm{sbm}$ \\
\hline No. 37 & $S+E$ & $S$ & sbm $\quad G$ \\
\hline No. 38 & $\mathrm{~S}+\mathrm{E}$ & $\mathrm{E}$ & sbm $\quad G$ \\
\hline No. 39 & $\mathrm{~S}+\mathrm{E}$ & $\mathrm{B}+\mathrm{S}$ & sbm \\
\hline No. 40 & $\mathrm{~S}+\mathrm{E}$ & $B+E$ & sbm \\
\hline No. 41 & $\mathrm{~S}+\mathrm{E}$ & $\mathrm{S}+\mathrm{E}$ & sbm $\quad G$ \\
\hline No. 42 & $\mathrm{~S}+\mathrm{E}$ & $\mathrm{B}+\mathrm{S}+\mathrm{E}$ & $\mathrm{sbm}$ \\
\hline es. & colo & a values & \\
\hline
\end{tabular}

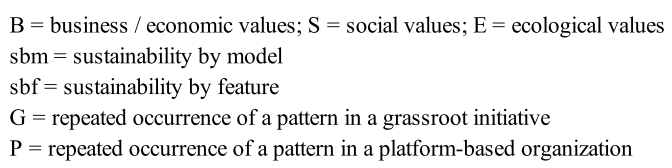

\begin{tabular}{|c|c|c|c|c|}
\hline & Central & Peripheral & Type & Obs. \\
\hline No. 43 & $\mathrm{~B}+\mathrm{S}+\mathrm{E}$ & $\mathrm{B}$ & & $P$ \\
\hline No. 44 & $\mathrm{~B}+\mathrm{S}+\mathrm{E}$ & S & sbf & \\
\hline No. 45 & $\mathrm{~B}+\mathrm{S}+\mathrm{E}$ & $\mathrm{E}$ & sbf & \\
\hline No. 46 & $\mathrm{~B}+\mathrm{S}+\mathrm{E}$ & $\mathrm{B}+\mathrm{S}$ & sbf & $P$ \\
\hline No. 47 & $\mathrm{~B}+\mathrm{S}+\mathrm{E}$ & $\mathrm{B}+\mathrm{E}$ & sbf & \\
\hline No. 48 & $\mathrm{~B}+\mathrm{S}+\mathrm{E}$ & $\mathrm{S}+\mathrm{E}$ & $\mathrm{sbf}$ & \\
\hline No. 49 & $\mathrm{~B}+\mathrm{S}+\mathrm{E}$ & $\mathrm{B}+\mathrm{S}+\mathrm{E}$ & & $\mathrm{P}$ \\
\hline
\end{tabular}

\section{Sustainability by Model}

How organizations in the two previously identified categories make use of the feature-values combinations and the optional strategies becomes clear when we color the network of features according to the combinations of addressed values (see Fig. 6).

The core of the grassroots category at the top of the figure is formed by a stationary system that primarily caters to social values and service teams that address social and ecological values. In the periphery, two features are similarly relevant for social and ecological values ("regional scope" and "no verification necessary"), while other features predominantly address social values ("locally bound system," "no registration required," "no compensation," "volunteer support," and "income via donation") or ecological values ("no website," "no mobile version," and "no social media"). None of these features of the grassroots category has a higher relevance for economic values. Instead, core and periphery features are primarily linked to sustainability values (see, for instance, no. 13 and no. 41 in Fig. 6). Because features at the core and in the first ring of the periphery are densely connected, we can conclude that organizations in the grassroots category apply the "sustainable by model" strategy to connect features and values.

This observation is consistent with results from conceptual and qualitative work on local initiatives in the sharing economy (Cohen and Muñoz 2016; Light and Miskelly 2015; Wekerle and Classens 2015). The values promised by organizations in the grassroots category are in line with expectations of two out of three perspectives in terms of what the purpose of the sharing economy should be. The sustainability transition perspective (Agyeman 2013; Botsman and Rogers 2010) suggests that the purpose of the sharing field is to facilitate a societal transition toward greater sustainability by pursuing social and ecological goals. The alternative economy perspective (Benkler 2017; Rifkin 2014; Sundararajan 2013) suggests that the purpose of the sharing economy is to create an alternative economic system by increasing the relevance of values, particularly social ones. We can assume that proponents of both perspectives will recognize and positively evaluate the grassroots initiatives category as fulfilling the shared purpose of transforming society and economy toward more sustainability. We would expect less favorable evaluations of this category from proponents of the business model innovation perspective (Amit and Zott 2012; Brynjolfsson and Saunders 2009; Weill and Woerner 2015) due to the missing link of grassroots to economic values and because of the relative unimportance of digital technologies and the Internet for grassroots initiatives.

\section{Sustainability by Feature}

The core of the platform-based organizations category is formed by features that are predominantly relevant for economic values ("provide online platform," "registration required," "platform transaction handling," and "online payment system") or are used to address any type of value ("mediating function," "online booking system," and "trust toward consumers"). In the periphery of this category, three sets of features show up: The first set contains peripheral 


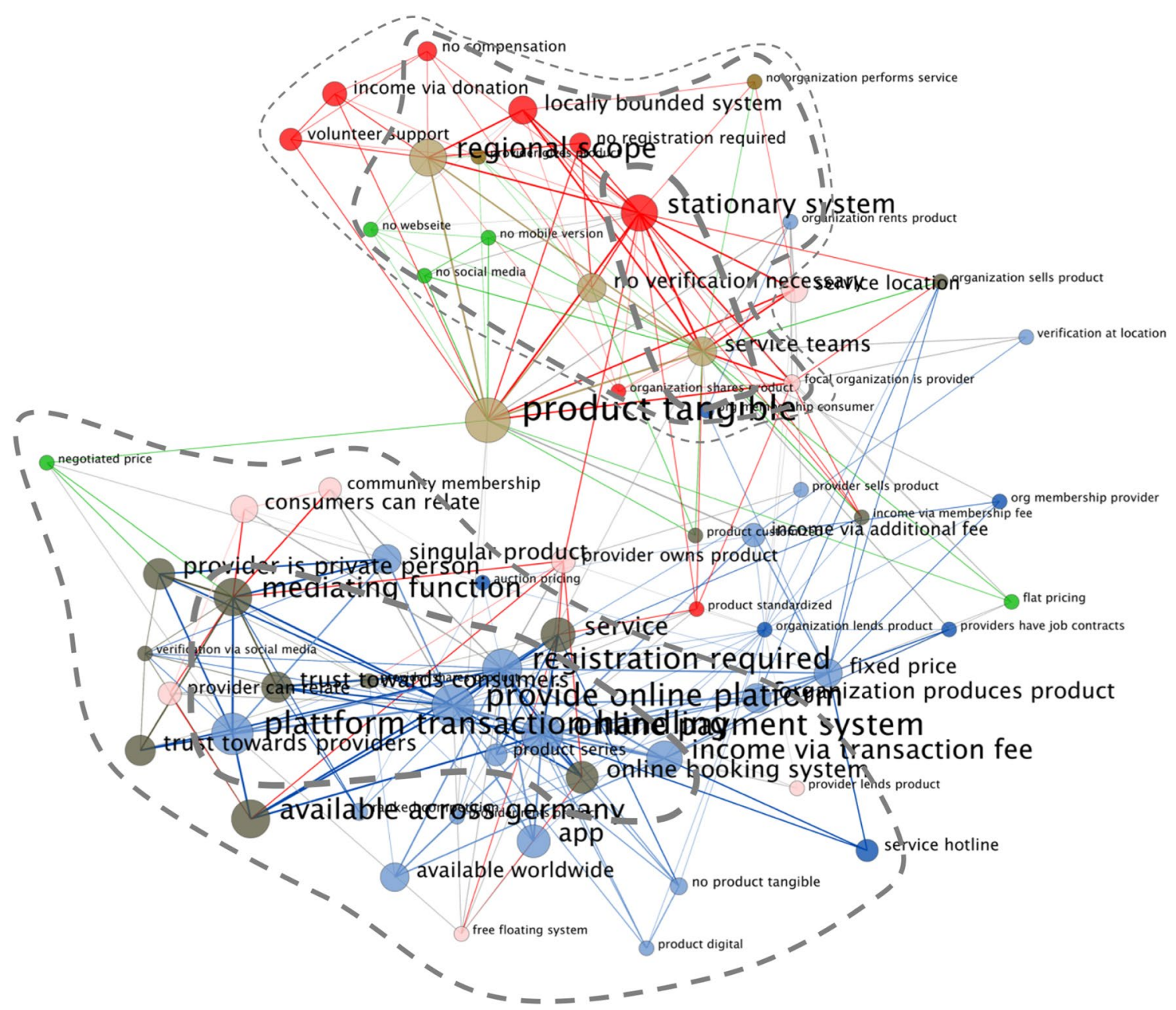

Fig. 6 Linkages between features and values. Nodes: features. Size of nodes: highest average percentage of a feature's occurrence for social, ecological or economic values. Color of nodes: red = social; green = ecological; blue = economic; light brown = ecological and social; light red $=$ economic and social; light green $=$ economic and ecologi-

features that primarily address economic values ("available worldwide," "app," "digital product," and "no tangible product"). These optional features are applied by prototypical platform-based organizations, which operate worldwide or focus on digital products. A second set contains features without any particular link to values ("available across Germany," "trust toward providers," "provider is a private person"). These optional features can be combined with any value proposition. The last set of features ("community membership," "consumer can relate," and "provider can trust") combine economic and social values. These features can be added to the core features to present organizations of this category as socially responsible. To summarize, the platform category includes features that are linked to economic or unspecific values at its core and features that are linked to unspecific values or to social and economic values at its periphery (see, for instance, no. 4 and no. 7 in cal (not used); dark brown = ecological, social and economic. Relationships: main co-occurrences for each feature. Borders: core $=$ thick line; periphery distance $1=$ medium line; periphery distance $2=$ thin line. Positioning: Fruchterman-Reingold

Fig. 6). Therefore, we can conclude that organizations in the platform-based category use the "sustainable by feature" strategy to connect features and values.

From a business model innovation perspective (Amit and Zott 2012; Brynjolfsson and Saunders 2009; Weill and Woerner 2015), the purpose of the sharing economy is to develop innovative business models based on digital technologies that make it possible to create economic value by unleashing previously untapped value from privately owned resources (Kenney and Zysman 2016). Our results from the platform category, with its features designed to enable transactions between users or providers and users of resources, its reliance on digital technologies, and its promised values that favor economic goals at its core and sustainable goals at the periphery, nicely fulfill the expectations of proponents of this perspective. Different evaluations of the platform category can, however, be expected 


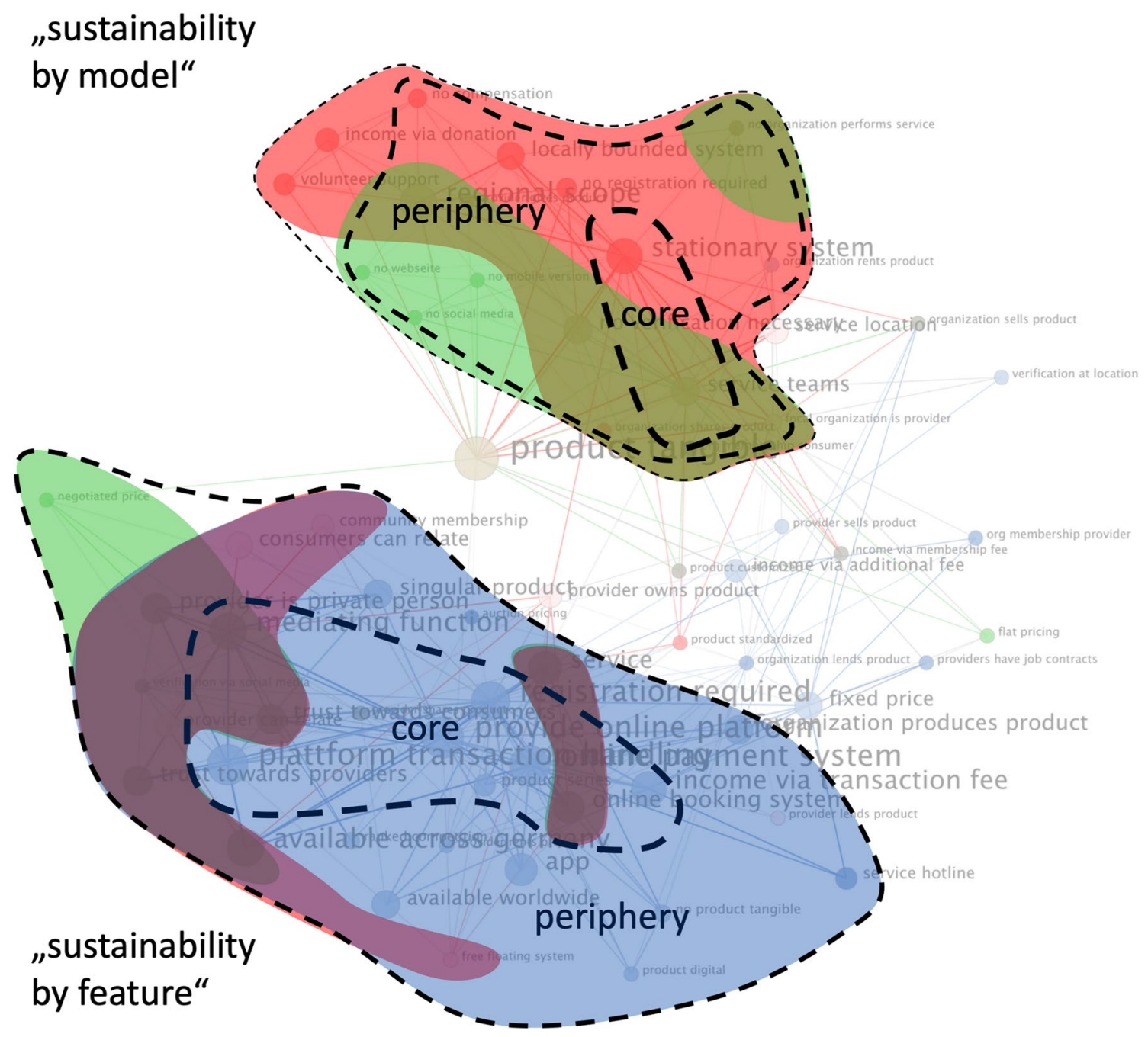

Fig. 7 Core and periphery of categories marked with values. Nodes: features. Size of nodes: highest average percentage of a feature's occurrence for social, ecological or economic values. Relationships: main co-occurrences for each feature. Borders: core $=$ thick line; periphery distance $1=$ medium line; periphery distance $2=$

from proponents of the other perspectives regarding what the purpose of the sharing field should be. Both the alternative economy perspective (Benkler 2017; Rifkin 2014) and the sustainability transition perspective (Agyeman 2013; Botsman and Rogers 2010) emphasize social and ecological values, which organizations in the platform category address only with selected peripheral features. We can assume that proponents of the alternative economy and sustainability transition perspectives would not find the "sustainability by feature" strategy credible, nor would they likely recognize organizations following this strategy as legitimate members of the sharing economy. Attempts to address sustainability values by adding peripheral thin line. Areas: red $=$ social; green $=$ ecological; blue $=$ economic . light brown $=$ ecological and social; light purple $=$ economic and social; dark purple $=$ social, ecological, and economic. Positioning: Fruchterman-Reingold

features could be criticized as "sharewashing" (Belk 2014; Kalamar 2013) or could be perceived as a form of windowdressing (Bansal and Kistruck 2006; Bhattacharya and Sen 2004; Connors et al. 2017).

To highlight the differences between the strategies "sustainability by model" used by grassroot initiatives and "sustainability by feature" applied by platform-based organizations, we colored core and periphery of both clusters accordingly (see Fig. 7). 


\section{Discussion}

Our study traced the self-representations of sharing organizations vis-à-vis ongoing debates about the purpose of the sharing economy and characteristics of proper sharing organizations. The observed configuration of categories contributes to interpretative analyses of categories in organizational fields. The identified split between categories contrasts debates about the sharing economy with positions of sharing organizations. The analyzed patterns of value-laden features at the core and periphery of these categories deepen our understandings of potential and actual legitimation strategies in the sharing economy.

\section{Interpretative Analysis of Categories in Organizational Fields}

To study organizations' positioning in fields, we combined two streams of institutional research-field analysis and category analysis - that are congruent in their fundamental theoretical assumptions. Combining these two streams in an empirical study facilitates cross-learning between field analysis and category analysis.

Empirical studies of categories often rely on the detailed analysis of one focal category and its differences from other categories (Delmestri and Greenwood 2016; Negro et al. 2010). With the application of the organizational field concept to the analysis of categories, the multiplicity of existing forms and, in particular, similarities and differences between them become central (DiMaggio and Powell 1983). The applied sampling approach helped us to capture such a variety of forms throughout various application areas without starting with one focal category. Through a semantic network analysis, we were able to tease out differences between categories across these areas. By exemplifying how a multiplicity of forms and the configuration of categories in a field can be reconstructed, we contribute to methodological debates about field analyses (Powell and Oberg 2017) and categories (Carroll and Swaminathan 2000; Hannan et al. 2012; Hsu 2006).

Capturing multiple forms in a field leads to the question of how these forms are related to each other. The applied relational view on features helps to understand the configuration of forms and categories in detail. It allows us to interpret the meaning of a single feature by taking its direct neighboring features into account. This relational analysis of meaning structures transfers an interpretative analysis of institutionalized roles (Jancsary et al. 2017; Meyer and Höllerer 2010; Mohr 1994) to the analysis of organizational forms and categories. Furthermore, the relational analysis enables teasing out differences between core features and peripheral features. This solves a recurring problem in the study of emerging categories about the relevance of individual features for overlaps and differences between categories (Hannan et al. 2012; Rao et al. 2005).

Analyzing categories from a field perspective raises the question of how specific categories contribute to the shared purpose of a field. By distinguishing organizational characteristics and values, we found an empirical solution to answer this question. This distinction follows a long tradition of sociological research about the relationship between forms of coordination and societal values (Ringer 1997; Weber 1978) and expands it to a field analysis that recognizes the distribution of values, norms, and cultural elements across organizations (Oberg et al. 2017; Powell and Oberg 2017). The resulting analysis of propositions of categories on a field level makes it possible to observe a double split within the emerging field of the sharing economy: The two observed categories are split in terms of their organizational characteristics and value propositions.

\section{Categories Versus Debates}

The observed double split is in line with some positions in debates on the purpose of the field and organizational characteristics, while it contrasts others.

Our insights on organizational characteristics contrast those of sharing-economy observers, who assume that the sharing economy is populated by organizational forms that are quite diverse (e.g., Botsman and Rogers 2010; Heinrichs 2013; Martin 2016; Stokes et al. 2014). In contrast, we observed more similarities and only found two categories of forms. Our empirical results for the case of Germany show that characteristics such as non-monetary exchanges, offline models, and locally bound activities fall into one category, while the characteristics of monetary exchange, online models, and national/global orientation of activities fall into a second category. This observed split resonates with previously described dichotomies to categorize sharing-economy organizations, such as monetary versus nonmonetary transactions (e.g., Voytenko Palgan et al. 2017) or locally bound versus non-localized organizations (e.g., Cohen and Muñoz 2016). Those who hold other positions also refer to these dichotomies but use them as inclusion/ exclusion criteria when they put forward their understanding of the sharing economy. For instance, some work focuses on online models, thereby implicitly excluding offline models from the sharing economy (e.g., Hamari et al. 2016). Other contributions are more explicit when they argue that, for example, organizations enabling monetary exchanges should not be considered part of the sharing economy (e.g., Belk 2014). However, because most existing work focuses on 
selected dichotomies, it has so far not been clear how they come together.

On the promotion of values, we observed a split between social and ecological values on the one hand and primarily economic values on the other hand. This split is in contrast to positions in debates suggesting that new forms of sharing can overcome conflicts among social, ecological, and economic goals and that sharing organizations can address all three value types simultaneously (e.g., Botsman and Rogers 2010). According to these positions, to overcome old conflicts between societal and economic progress could have become a shared purpose for the field of the sharing economy. Our analysis based on self-representations, however, reveals that there is no shared purpose in the sense that all organizations address social, ecological, and economic goals simultaneously.

The insights of this study thus resonate with positions in debates suggesting that attempts to align all three types of values would lead to an "escalation of tensions and unfulfilled promises" (Acquier et al. 2017, p. 8). More precisely, the observed split between economic and sustainability values is in line with work suggesting that sharing organizations can be categorized based on whether they put forward economic goals such as their own profit or the creation of new economic activity among their users, or whether they are oriented toward achieving social and ecological goals as a non-profit organization (e.g., Schor 2014). Other work identifies a similar split; however, it does not use this split to distinguish between types of sharing organizations but to exclude organizations focusing on economic values. It has been proposed that the only organizations that should be considered part of the sharing economy are those that contribute to social or ecological goals by, for instance, enabling access to underutilized goods (Frenken and Schor 2017) or strengthening the sense of community (Belk 2014). Hence, while these contributions identify a similar split with regard to values as we do, they draw different conclusions from this split and suggest that organizations that do not enhance social and ecological goals should be excluded from the sharing category altogether. Instead, our sampling based on media articles reveals that prototypical organizations of the two categories with different values are still perceived as being part of the same field. Nevertheless, the identified split might explain why debates about both the purpose of the sharing economy and categories within it continue (Frenken and Schor 2017; Kornberger et al. 2018; Martin 2016). If the split on the organizational level is further recognized in debates about the sharing economy, two subfields might emerge.

\section{Legitimation Strategies in the Sharing Economy}

Organizations interested in belonging to the sharing economy are confronted with debates that open up many possibilities to combine organizational characteristics and to address social, ecological, and economic values. The debates are so fragmented that every combination of characteristics and values seems possible. Furthermore, when we identified current categories as clusters of features, we learned that there are several options to connect core or peripheral features with social and ecological values. With the observed "sustainability by model" and "sustainability by feature" strategies, the number of available options to create organizational forms in the sharing economy multiplies.

Against these available options, we responded to the call to study sharing organizations (Gerwe and Silva 2018; Voytenko Palgan et al. 2017) and observe actually realized options. We found that prototypical organizations of different areas of application in Germany instantiate only a small number of categories from among the available options. Two field-related mechanisms might contribute to this limitation of available categories: Instead of testing one of the many options outlined in debates, many organizations observe other organizations that have similar positions in society and mimic their characteristics (DiMaggio and Powell 1983). Even if they do not mimic all characteristics, in an emerging field, they might hide differences when it comes to the presentation of self in everyday life to gain legitimacy (Goffman 1959). Regarding presenting oneself as a good organization with the right approach, only two categories remained at the time of our data collection. As a consequence, individual organizations that try to show publicly that they belong to one or the other category are confronted with an interrelated bundle of characteristics, values, and legitimation strategies.

Based on our sample, we do not know whether the observed bundling is specific to Germany and the particular point in time of our data collection. Research on the sharing economy in other cultural and economic settings (Hira 2017) suggests that categories vary across socioeconomic systems, but systematic comparisons of categories at the field level are still missing. It would be interesting to see to what extent observed categories are universal and which categories are local solutions (Drori et al. 2014). Research on categories shows that the bundling of categories and societal values can be stable over a long time period but might change during other periods (e.g., Delmestri and Greenwood 2016). Given the dynamic development of the sharing economy, such a change is likely when we gain more societal knowledge about the actual impacts of specific models (Frenken and Schor 2017). We 
are looking forward to two exciting research streams in the future: the comparison of value propositions with actual effects of sharing organizations and the development of sharing categories in fields over time.

Acknowledgments We wish to thank the German Federal Ministry of Education and Research for funding our research (Grant Nos. 01UT1408A and 01UT1408E).

\section{Compliance with Ethical Standards}

Conflict of interest All authors declare that they have no conflicts of interest.

Ethical Approval This article does not contain any studies with human participants performed by any of the authors.

Open Access This article is distributed under the terms of the Creative Commons Attribution 4.0 International License (http://creativeco mmons.org/licenses/by/4.0/), which permits unrestricted use, distribution, and reproduction in any medium, provided you give appropriate credit to the original author(s) and the source, provide a link to the Creative Commons license, and indicate if changes were made.

\section{References}

Acquier, A., Daudigeos, T., \& Pinkse, J. (2017). Promises and paradoxes of the sharing economy: An organizing framework. Technological Forecasting and Social Change, 125, 1-10.

Agyeman, J. (2013). Introducing just sustainabilities: Policy, planning, and practice. New York: Zed Books Ltd.

Amit, R., \& Zott, C. (2012). Creating value through business model innovation. MIT Sloan Management Review, 53(3), 41-49.

Bansal, P., \& Kistruck, G. (2006). Seeing is (not) believing: Managing the impressions of the firm's commitment to the natural environment. Journal of Business Ethics, 67(2), 165-180.

Bartkus, B. R., \& Glassman, M. (2008). Do firms practice what they preach? The relationship between mission statements and stakeholder management. Journal of Business Ethics, 83(2), 207-216.

Bauwens, M. (2005). The political economy of peer production. CTheory, $12-1$.

Belk, R. (2010). Sharing. Journal of Consumer Research, 36(5), $715-734$.

Belk, R. (2014). Sharing versus pseudo-sharing in Web 2.0. Anthropologist, 18(1), 7-23.

Benecke, D. W. (2008). Social and ecological market economy-A General Overview. In: The Social and Ecological Market Economy-A Model for Asian Development? Eschborn: GTZ.

Benkler, Y. (2017). Peer production, the commons, and the future of the firm. Strategic Organization, 15(2), 264-274.

Berger, P. L., \& Luckmann, T. (1991). The social construction of reality: A treatise in the sociology of knowledge. London: Penguin Uk.

Bhattacharya, C. B., \& Sen, S. (2004). Doing better at doing good: When, why, and how consumers respond to corporate social initiatives. California Management Review, 47(1), 9-24.

Boell, S. K., \& Cecez-Kecmanovic, D. (2014). A hermeneutic approach for conducting literature reviews and literature searches. CAIS, 34,12 .
Bolton, R., \& Hannon, M. (2016). Governing sustainability transitions through business model innovation: Towards a systems understanding. Research Policy, 45(9), 1731-1742.

Boons, F., \& Lüdeke-Freund, F. (2013). Business models for sustainable innovation: State-of-the-art and steps towards a research agenda. Journal of Cleaner Production, 45, 9-19.

Botsman, R. (2013). The sharing economy lacks a shared definition. Fast Company, 21, 2013.

Botsman, R., \& Rogers, R. (2010). What's mine is yours: The rise of collaborative consumption. New York: HarperBusiness.

Brynjolfsson, E., Hu, Y., \& Smith, M. D. (2003). Consumer surplus in the digital economy: Estimating the value of increased product variety at online booksellers. Management Science, 49(11), $1580-1596$.

Brynjolfsson, E., \& Saunders, A. (2009). Wired for innovation: How information technology is reshaping the economy. Cambridge, MA: MIT Press.

Buttle, M., Vyas, D., \& Spinks, C. (2013). Evaluating the financial viability and resource implications for new business models in the clothing sector. Banbury: Wrap.

Carley, K. M., \& Kaufer, D. S. (1993). Semantic connectivity: An approach for analyzing symbols in semantic networks. Соттиnication Theory, 3(3), 183-213.

Carley, K. M., \& Palmquist, M. (1992). Extracting, representing, and analyzing mental models. Social Forces, 70(3), 601-636.

Carroll, G. R., \& Swaminathan, A. (2000). Why the microbrewery movement? Organizational dynamics of resource partitioning in the US brewing industry. American Journal of Sociology, 106(3), $715-762$.

Castelló, I., Etter, M., \& Årup Nielsen, F. (2016). Strategies of legitimacy through social media: The networked strategy. Journal of Management Studies, 53(3), 402-432.

Cheng, M. (2016). Current sharing economy media discourse in tourism. Annals of Tourism Research, 60, 111-114.

Cheng, M., Edwards, D., Darcy, S., \& Redfern, K. (2016). A trimethod approach to a review of adventure tourism literature: Bibliometric analysis, content analysis, and a quantitative systematic literature review. Journal of Hospitality \& Tourism Research, 42(6), 997-1020.

Clemens, E. S. (1993). Organizational repertoires and institutional change: Women's groups and the transformation of US politics, 1890-1920. American Journal of Sociology, 98(4), 755-798.

Codagnone, C., \& Martens, B. (2016). Scoping the sharing economy: Origins, definitions, impact and regulatory issues. European Commission: Joint Research Center-Technical Report.

Cohen, B., \& Kietzmann, J. (2014). Ride on! Mobility business models for the sharing economy. Organization \& Environment, 27(3), 279-296.

Cohen, B., \& Muñoz, P. (2016). Sharing cities and sustainable consumption and production: Towards an integrated framework. Journal of Cleaner Production, 134, 87-97.

Connors, S., Anderson-MacDonald, S., \& Thomson, M. (2017). Overcoming the 'Window Dressing' effect: Mitigating the negative effects of inherent skepticism towards corporate social responsibility. Journal of Business Ethics, 145(3), 599-621.

De Bakker, F. G. A., \& Hellsten, I. (2013). Capturing online presence: Hyperlinks and semantic networks in activist group websites on corporate social responsibility. Journal of Business Ethics, 118(4), 807-823.

Delmestri, G., \& Greenwood, R. (2016). How Cinderella became a queen: Theorizing radical status change. Administrative Science Quarterly, 61(4), 507-550.

DiMaggio, P. (1997). Culture and cognition. Annual Review of Sociology, 23(1), 263-287.

DiMaggio, P. J., \& Powell, W. W. (1983). The iron cage revisited: Institutional isomorphism and collective rationality in 
organizational fields. American Sociological Review, 48(2), $147-160$.

Distel, R. (2010). Graph theory. Berlin: Springer.

Drori, G. S., Höllerer, M. A., \& Walgenbach, P. (2014). Unpacking the glocalization of organization: From term, to theory, to analysis. European Journal of Cultural and Political Sociology, 1(1), 85-99.

Durand, R., \& Paolella, L. (2013). Category stretching: Reorienting research on categories in strategy, entrepreneurship, and organization theory. Journal of Management Studies, 50(6), $1100-1123$

Fiss, P. C., \& Zajac, E. J. (2006). The symbolic management of strategic change: Sensegiving via framing and decoupling. The Academy of Management Journal, 49(6), 1173-1193.

Freeman, R. E. (2010). Strategic management: A stakeholder approach. Cambridge, UK: Cambridge University Press.

Freeman, R. E., \& Reed, D. L. (1983). Stockholders and stakeholders: A new perspective on corporate governance. California Management Review, 25(3), 88-106.

Frenken, K., \& Schor, J. (2017). Putting the sharing economy into perspective. Environmental Innovation and Societal Transitions, 23, 3-10.

Fruchterman, T. M. J., \& Reingold, E. M. (1991). Graph drawing by force-directed placement. Software: Practice and Experience, 21(11), 1129-1164.

Gawer, A. (2014). Bridging differing perspectives on technological platforms: Toward an integrative framework. Research Policy, 43(7), 1239-1249.

Geels, F. W. (2002). Technological transitions as evolutionary reconfiguration processes: A multi-level perspective and a casestudy. Research Policy, 31(8), 1257-1274.

Geels, F. W. (2011). The multi-level perspective on sustainability transitions: Responses to seven criticisms. Environmental Innovation and Societal Transitions, 1(1), 24-40.

Geels, F. W., Hekkert, M. P., \& Jacobsson, S. (2008). The dynamics of sustainable innovation journeys. Technology Analysis \& Strategic Management, 20(5), 521-536.

Gerwe, O., \& Silva, R. (2018). Clarifying the sharing economy: Conceptualization, typology, antecedents, and effects. Academy of Management Perspectives. Retrieved from https://journals.aom. org/doi/pdf/10.5465/amp.2017.0010.

Goffman, E. (1959). The presentation of self in everyday life. New York: Anchor Books.

Gorenflo, N. (2015). How platform coops can beat death stars like uber to create a real sharing economy. Shareable.org. Retrieved from https://www.shareable.net/blog/how-platform-coops-can-beatdeath-stars-like-uber-to-create-a-real-sharing-economy.

Green, S. E. (2004). A rhetorical theory of diffusion. The Academy of Management Review, 29(4), 653-669.

Hamari, J., Sjöklint, M., \& Ukkonen, A. (2016). The sharing economy: Why people participate in collaborative consumption. Journal of the Association for Information Science and Technology, 67(9), 2047-2059.

Hannan, M. T., Pólos, L., \& Carroll, G. R. (2012). Logics of organization theory: Audiences, codes, and ecologies. Princeton, NJ: Princeton University Press.

Hart, C. (2018). Doing a literature review: Releasing the research imagination. Thousand Oaks, CA: Sage.

Heinrichs, H. (2013). Sharing economy: A potential new pathway to sustainability. GAIA-Ecological Perspectives for Science and Society, 22(4), 228-231.

Hinings, C., Logue, D., \& Zietsma, C. (2017). Fields, institutional infrastructure and governance. In R. Greenwood, C. Oliver, T. B. Lawrence, \& R. E. Meyer (Eds.), The Sage handbook of organizational institutionalism (pp. 163-189). London: SAGE.
Hira, A. (2017). Profile of the sharing economy in the developing world: Examples of companies trying to change the world. Journal of Developing Societies, 33(2), 244-271.

Hoffman, A. J. (1999). Institutional evolution and change: Environmentalism and the U.S. chemical industry. Academy of Management Journal, 42(4), 351-371.

Holton, J. A. (2007). The coding process and its challenges. In: The Sage handbook of grounded theory, (Part III) (pp. 265-289). London: Sage.

Hsu, G. (2006). Jacks of all trades and masters of none: Audiences' reactions to spanning genres in feature film production. Administrative Science Quarterly, 51(3), 420-450.

Hsu, G., \& Hannan, M. T. (2005). Identities, genres, and organizational forms. Organization Science, 16(5), 474-490.

Jancsary, D., Meyer, R. E., Höllerer, M. A., \& Barberio, V. (2017). Toward a structural model of organizational-level institutional pluralism and logic interconnectedness. Organization Science, 28(6), 1150-1167.

Kalamar, A. (2013). Sharewashing is the new greenwashing. $O p E d$ News. Retrieved from: https://www.opednews.com/articles/Share washing-is-the-New-Gr-by-Anthony-Kalamar-130513-834.html.

Kenney, M., \& Zysman, J. (2016). The rise of the platform economy. Issues in Science and Technology, 32(3), 61.

Kornberger, M., Leixnering, S., Meyer, R. E., \& Höllerer, M. A. (2018). Rethinking the sharing economy: The nature and organization of sharing in the 2015 refugee crisis. Academy of Management Discoveries, 4(3), 314-335.

Lepak, D. P., Smith, K. G., \& Taylor, M. S. (2007). Value creation and value capture: A multilevel perspective. Academy of Management Review, 32(1), 180-194.

Leydesdorff, L., \& Vaughan, L. (2006). Co-occurrence matrices and their applications in information science: Extending ACA to the Web environment. Journal of the American Society for Information Science and Technology, 57(12), 1616-1628.

Light, A., \& Miskelly, C. (2015). Sharing economy vs sharing cultures? Designing for social, economic and environmental good. Interaction Design and Architecture (S), 24, 49-62.

Mair, J., \& Reischauer, G. (2017). Capturing the dynamics of the sharing economy: Institutional research on the plural forms and practices of sharing economy organizations. Technological Forecasting and Social Change, 125, 11-20.

Malhotra, A., \& Van Alstyne, M. (2014). The dark side of the sharing economy... and how to lighten it. Communications of the $A C M$, 57(11), 24-27.

Martin, C. J. (2016). The sharing economy: A pathway to sustainability or a nightmarish form of neoliberal capitalism? Ecological Economics, 121, 149-159.

Martin, C. J., Upham, P., \& Budd, L. (2015). Commercial orientation in grassroots social innovation: Insights from the sharing economy. Ecological Economics, 118, 240-251.

Martin, E. W., \& Shaheen, S. A. (2011). Greenhouse gas emission impacts of carsharing in North America. IEEE Transactions on Intelligent Transportation Systems, 12(4), 1074-1086.

Massa, L., Tucci, C. L., \& Afuah, A. (2017). A critical assessment of business model research. Academy of Management Annals, 11(1), 73-104.

Mayring, P. (2014). Qualitative content analysis: Theoretical foundation, basic procedures and software solution. Klagenfurt: Social Science Open Access Repository.

McKelvey, B. (1982). Organizational systematics-taxonomy, evolution, classification. Oakland, CA: University of California Press.

McKelvey, B., \& Aldrich, H. (1983). Populations, natural selection, and applied organizational science. Administrative Science Quarterly, 28, 101-128. 
Meyer, J. W., \& Rowan, B. (1977). Institutionalized organizations: Formal structure as myth and ceremony. American Journal of Sociology, 83(2), 340-363.

Meyer, R. E., \& Höllerer, M. A. (2010). Meaning structures in a contested issue field: A topographic map of shareholder value in Austria. Academy of Management Journal, 53(6), 1241-1262.

Mohr, J. W. (1994). Soldiers, mothers, tramps and others: Discourse roles in the 1907 New York City charity directory. Poetics, 22(4), 327-357.

Morozov, E. (2013). The "sharing economy" undermines workers' rights. Financial Times. Retrieved from https://www.ft.com/ content/92c3021c-34c2-11e3-8148-00144feab7de.

Negro, G., Koçak, Ö., \& Hsu, G. (2010). Research on categories in the sociology of organizations. Categories in markets: Origins and evolution (pp. 3-35). Bingley: Emerald Group Publishing Limited.

Oberg, A., Korff, V. P., \& Powell, W. W. (2017). Culture and connectivity intertwined: Visualizing organizational fields as relational structures and meaning systems. In: Structure, Content and Meaning of Organizational Networks: Extending Network Thinking (pp. 17-47). Bingley: Emerald Publishing Limited.

Owyang, J. (2013, December 10). The next big thing you missed: The sharing economy goes corporate. wired.com. Retrieved from https://www.wired.com/2013/12/sharing-economy-goes-corpo rate/.

Owyang, J. (2016). Honeycomb 3.0: The collaborative economy market expansion. Retrieved from http://www.web-strategist.com/ blog/2016/03/10/honeycomb-3-0-the-collaborative-economymarket-expansion-sxsw/.

Padgett, J. F., \& Powell, W. W. (2012). The problem of emergence. The emergence of organizations and markets (pp. 1-29). Princeton, NJ: Princeton University Press.

Peyrefitte, J., \& David, F. R. (2006). A content analysis of the mission statements of United States firms in four industries. International Journal of Management, 23(2), 296.

Phillips, N., Lawrence, T. B., \& Hardy, C. (2004). Discourse and institutions. Academy of Management Review, 29(4), 635-652.

Powell, W. W., Horvath, A., \& Brandtner, C. (2016). Click and mortar: Organizations on the web. Research in Organizational Behavior, $36,101-120$.

Powell, W. W., \& Oberg, A. (2017). Networks and institutions. In R. Greenwood, C. Oliver, T. B. Lawrence, \& R. E. Meyer (Eds.), Sage handbook on organizational institutionalism (pp. 446-476). London: Sage.

Puschmann, T., \& Alt, R. (2016). Sharing economy. Business \& Information Systems Engineering, 58(1), 93-99.

Rao, H., Monin, P., \& Durand, R. (2005). Border crossing: Bricolage and the erosion of categorical boundaries in French gastronomy. American Sociological Review, 70(6), 968-991.

Rifkin, J. (2014). The zero marginal cost society: The internet of things, the collaborative commons, and the eclipse of capitalism. New York: St. Martin's Press.

Ringer, F. (1997). Max Weber's methodology: The unification of the cultural and social sciences. Cambridge, MA: Harvard University Press.

Rinne, A. (2018). The dark side of the sharing economy. Retrieved from https://www.weforum.org/agenda/2018/01/the-dark-sideof-the-sharing-economy/.

Ruef, M., \& Patterson, K. (2009). Credit and classification: The impact of industry boundaries in nineteenth-century America. Administrative Science Quarterly, 54(3), 486-520.
Scholz, T. (2016). Platform cooperativism-Challenging the corporate sharing economy. New York: Rosa Luxemburg Stiftung.

Schor, J. (2014). Debating the sharing economy. Journal of Self-Governance \& Management Economics, 4(3), 7-22.

Schor, J. B. (2017). Does the sharing economy increase inequality within the eighty percent? Findings from a qualitative study of platform providers. Cambridge Journal of Regions, Economy and Society, 10(2), 263-279.

Scott, S. G., \& Lane, V. R. (2000). A stakeholder approach to organizational identity. Academy of Management Review, 25(1), 43-62.

Slee, T. (2017). What's yours is mine: Against the sharing economy. New York: Or Books.

Stokes, K., Clarence, E., Anderson, L., \& Rinne, A. (2014). Making sense of the UK collaborative economy. London: Nesta.

Strang, D., \& Meyer, J. W. (1993). Institutional conditions for diffusion. Theory and Society, 22(4), 487-511.

Suchman, M. C. (1995). Managing legitimacy: Strategic and institutional approaches. The Academy of Management Review, 20(3), 571.

Sundararajan, A. (2013). From Zipcar to the sharing economy. Harvard Business Review. Online Edition. Retrieved from https:// hbr.org/2013/01/from-zipcar-to-the-sharing-eco.

Sundararajan, A. (2014). Peer-to-peer businesses and the sharing (collaborative) economy: Overview, economic effects and regulatory issues. Written testimony for the hearing titled the power of connection: Peer to peer businesses.

Voytenko Palgan, Y., Zvolska, L., \& Mont, O. (2017). Sustainability framings of accommodation sharing. Sustainability Perspectives on the Sharing Economy, 23, 70-83.

Wasserman, S., \& Faust, K. (1994). Social network analysis: Methods and applications. Cambridge/New York: Cambridge University Press.

Weber, M. (1978). Economy and society: An outline of interpretive sociology (Vol. 1). Oakland, CA: University of California Press.

Weill, P., \& Woerner, S. L. (2015). Thriving in an increasingly digital ecosystem. MIT Sloan Management Review, 56(4), 27-34.

Weitzman, M. L. (1984). The share economy: Conquering stagflation. Cambridge, MA: Harvard University Press.

Wekerle, G. R., \& Classens, M. (2015). Food production in the city: (re)Negotiating land, food and property. Local Environment, 20(10), 1175-1193.

Westphal, J. D., \& Zajac, E. J. (1998). The symbolic management of stockholders: Corporate governance reforms and shareholder reactions. Administrative Science Quarterly, 43(1), 127-153.

Whelan, G., \& Gond, J.-P. (2017). Meat your enemy: Animal rights, alignment, and radical change. Journal of Management Inquiry, 26(2), 123-138.

Yunus, M., Moingeon, B., \& Lehmann-Ortega, L. (2010). Building social business models: Lessons from the Grameen experience. Long Range Planning, 43(2-3), 308-325.

Zuckerman, E. W. (1999). The categorical imperative: Securities analysts and the illegitimacy discount. American Journal of Sociology, 104(5), 1398-1438.

Publisher's Note Springer Nature remains neutral with regard to jurisdictional claims in published maps and institutional affiliations. 